\title{
Seismic Hazard and Risk due to Induced Earthquakes at a Shale Gas Site
}

\author{
Benjamin Edwards ${ }^{1 *}$, Helen Crowley², Rui Pinho ${ }^{3}$, Julian J Bommer ${ }^{4}$
}

1. School of Environmental Sciences, University of Liverpool, UK

2. Independent Consultant, Pavia, Italy

3. Civil Engineering Department, University of Pavia, Pavia, Italy

4. Civil \& Environmental Engineering, Imperial College London, London, UK

* Corresponding author

Jane Herdman Building

School of Environmental Sciences

University of Liverpool

Liverpool

L69 3GP

United Kingdom

ben.edwards@liverpool.ac.uk

Keywords: seismic hazard, seismic risk, induced seismicity, hydraulic fracturing. 


\begin{abstract}
Hydraulic fracturing of the first shale gas well at Preston New Road (PNR), Blackpool, UK in late 2018 marked the end of a seven-year UK-wide moratorium on fracking. Despite a strict Traffic Light System being in place seismic events up to $M\llcorner 2.9$ were induced. The $M\llcorner 2.9$ event was accompanied by reports of damage and was assigned EMS-98 intensity VI by the British Geological Survey. The moratorium was subsequently reinstated in late 2019. The study here presents a pseudo-probabilistic seismic risk analysis and is applied to the larger of the induced events at PNR, in addition to hypothetical larger events.

Initially, site characterization analysis is undertaken using direct and indirect methods. These analyses show low-velocity deposits dominate the region $\left(\overline{V_{s 30}}=227 \mathrm{~m} / \mathrm{s}\right)$. We test existing ground motion prediction equations using spatially-dependent $V_{s 30}$ to determine applicability to the recorded waveform data and produce a referenced empirical model. Predicting median and $84^{\text {th }}$ percentile peak ground velocity fields we subsequently determine macroseismic intensities. Epicentral intensities of IV, IV-V and VI-VII are predicted for the observed $\mathrm{M} L 2.9$, and hypothetical $M\llcorner 3.5$ and 4.5 scenarios, respectively.

A probabilistic analysis of damage is performed for 3500 ground-motion realisations $(2.1 \leq \mathrm{M} L \leq 4.5)$ using the OpenQuake-engine with nonlinear dynamic analysis undertaken to define building fragility. Based on these analyses, the onset of cosmetic damage (DS1) in terms of median risk is observed for the $\mathrm{M} L 2.9$ event. Mean modelled occurrences of DS1 and DS2 (minor structural damage), 75 and 10 instances, respectively, are consistent with reported damage (DS1:97, DS2:50). Significant occurrences (median $\geq 30$ buildings) of DS2, DS3 and DS4 (minor to major structural damage) are likely for $\mathrm{M}$ 3.5, 4.0 and 4.5 events, respectively. However, by comparing reported damage with modelled damage due to the $M_{\llcorner} 2.9$ event and considering the fact that low macroseismic intensities $(E M S-98<4)$ are often not reported by the public, we conclude that the previously assigned intensity of $\mathrm{VI}$ is too high, with $\mathrm{V}$ being more appropriate.
\end{abstract}




\section{Introduction}

Seismic risk represents one of the biggest challenges when attempting to exploit resources in the upper crust. Such activities vary from geothermal energy and carbon capture storage to conventional mining and onshore unconventional hydrocarbon extraction. In all cases where subsurface stresses are perturbed (e.g. through fluid injection, or material extraction) induced seismicity is possible and presents a significant hazard that can result in increased risk to the exposed population and building stock. The work presented here demonstrates an approach to quantify and, consequently, predict this risk (conditional on specific events), with application to an unconventional hydrocarbon site in the north of England at Preston New Road (PNR), Blackpool.

The PNR site aimed to extract shale gas through hydraulic fracturing horizontal wells drilled into the Bowland Shales (Clarke et al., 2019). The Bowland Shales are present across much of northern England with recent studies determining significant, albeit widely variable, 'gas inplace'. Central estimates range from 140 trillion (Whitelaw et al., 2019) to 1329 trillion cubic feet (Andrews, 2013), depending on approach taken. The PNR site is operated by Cuadrilla Resources, who previously undertook hydraulic fracturing at the only other onshore shale gas well in the UK, which lies $4 \mathrm{~km}$ away at Preese Hall, Blackpool (Clarke et al., 2014). Operations at the Preese Hall site in 2011 culminated in a local magnitude $\left(\mathrm{M}_{\mathrm{L}}\right) 2.3$ earthquake and subsequently a seven-year moratorium on hydraulic fracturing in the UK. During this period an extensive review into hydraulic fracturing was undertaken. As part of this, Green et al. (2012) recommended the introduction of a Traffic Light System (TLS, Bommer et al., 2006) for induced seismicity, which has been used at various sites worldwide to different levels of success (Deichmann and Giardini 2009; Kwiatek et al., 2019; Baisch et al., 2019). The TLS defines three levels: green, amber and red, with $M_{L} 0$ and 0.5 triggering the amber and red levels, respectively. These thresholds were designed to avoid any felt seismicity (with an assumed minimum 'felt' threshold at $M\llcorner$ 1.5), even in the case of a trailing event with potential increase of one magnitude unit (Green et al., 2012). In the UK's TLS, the amber level necessitates a higher level of monitoring and analysis, but otherwise no operational curtailment. A 'red light' leads to a pause of operations for at least 18 hours, during which a review of the earthquake is undertaken by the regulator (the Oil and Gas Authority, OGA). If satisfied that the seismic activity is under control, the OGA will then authorise a resumption of production.

Seismicity relevant to the TLS (i.e. $M_{L}>0$ ) at PNR was monitored using a surface network of broadband 3-component seismometers operated by Cuadrilla Resources (the operator), the British Geological Survey (BGS) and the University of Liverpool (UoL) (Figure 1). The combined TLS network is dense in the epicentral region (with inter-station spacing $\sim 0.5-2 \mathrm{~km}$ ) allowing for the detection of micro-seismicity, with a magnitude of completeness around $M_{L} 0$. Data from all instruments were streamed in real-time to the BGS who were responsible for event detection, location and magnitude characterisation. Routine (STA/LTA) detection algorithms 
were employed by the BGS to quickly detect seismicity. Earthquake magnitudes were assigned by the BGS using a revised $M_{L}$ scale (Luckett et al., 2018), which extended the existing national scale's validity to distances less than $10-20 \mathrm{~km}$.

The first shale gas well at Preston New Road was actively fracked for 3-weeks in the period between $15^{\text {th }}$ October and $17^{\text {th }}$ December 2018. During the two-month period between the onset and cessation of hydraulic fracturing, 57 seismic events were detected and located by the BGS (Figure 1). Several months later, during August 2019, a second well, adjacent and shallower to the first, was hydraulically fractured. Between $15^{\text {th }}$ August and $6^{\text {th }}$ October, 2019, a further 135 events were detected on the TLS network. The magnitude of detected events was small during the first period of activity $\left(-0.8 \leq M_{\llcorner} \leq 1.5\right)$, with the largest $(M\llcorner 1.1$ and 1.5$)$ assigned macroseismic intensity (EMS-98) II. Three 'amber' and 6 'red-light' events were reported by the operator (Cuadrilla Resources 2019a). In total, 17 events during 2018 fell into the 'amber light' category and 8 the 'red light' category $\left(M_{L} \geq 0.5\right)$ in terms of catalogue magnitude alone. Note that in terms of regulatory reporting, the definition of 'amber' event strictly required active pumping, which is not considered here. Furthermore, differences in magnitude precision means that reporting is sometimes inconsistent between the BGS (who report $M_{L}$ to 1 decimal place) and the operator (who report to 2 decimal places).

During hydraulic fracturing of the second well in 2019 both the quantity (135) and magnitude $\left(-1.7 \leq M_{L} \leq 2.9\right)$ of detected events was larger. The BGS catalogue shows that until the evening of $21^{\text {st }}$ August, 67 events were detected, with the largest three events having magnitudes of $M L=0.0$. Subsequently, at 19:46 a 'red-light' $M\llcorner 1.6$ occurred, which led to a temporary cessation of operations for 18 hours. In the following days, three further 'red-light' events were detected at $M\llcorner 0.9,1.0$ and 1.1, before the two largest events in the sequence occurred: $M\left\llcorner 2.1\right.$ at 22:01 on the $24^{\text {th }}$ and $M\left\llcorner 2.9\right.$ at 07:30 on the $26^{\text {th }}$ August. Operations were permanently suspended by the regulator at this point. However, seismicity continued with 25 events detected up until $6^{\text {th }}$ October, two of which were 'red-light' events that occurred within 24 hours of the largest $M\llcorner 2.9$ earthquake.

This paper documents a hazard and risk assessment approach utilising available models and data for the prediction of ground motions, macroseismic intensity and seismic risk. First, we present both in situ and indirect measurements and interpretation undertaken to characterise the ground conditions around PNR. We then present an analysis of seismic waveform data recorded on the surface TLS monitoring networks. The performance of available ground motion models is assessed and the referenced empirical approach (Bommer et al., 2006; Atkinson, 2008) is used to define a PNR-specific ground motion prediction equation (GMPE). We then investigate the impacts of various earthquake scenarios, first in terms of the ground motions predicted, and then, through a probabilistic scenario-based damage analysis, their impact on the built environment. 


\section{TLS Monitoring and Site Characterisation}

Waveform data were streamed from 26 seismic stations within $25 \mathrm{~km}$ of the PNR site. Nine stations were operated by the BGS, 9 by UoL and 8 by the operator (Figure 1). All stations comprised of a 3-component broadband sensor and 24-bit datalogger. The operator's instruments are all located within approximately $5 \mathrm{~km}$ of the well (aimed at lowering the detection limit to $M_{L} 0$ ), while BGS and UoL operate more disperse networks (with a radius of around $20 \mathrm{~km}$ ).

\section{Shear-Wave Velocity Models and $V_{s 30}$}

Site amplification effects lead to significant spatial differences in ground motion and are often correlated with regions of high ground motion intensity and damage. Shear-wave velocity $\left(V_{s}\right)$ of the upper $30 \mathrm{~m}\left(V_{s 30}\right)$ of soil and/or rock is a widely-used proxy for such effects (Boore et al., 2014). The strategy for the assessment of site amplification at PNR was to target specific superficial geology present in the area with direct measurements of $V_{s 30}$, followed by a wider analysis using indirect measurements at each of the seismometer sites.

Sites L001 (glacial till), L003 (peat) and L009 (blown sand) cover the range of superficial geology found across the region. Following Foti et al. (2017), the Multi-channel Analysis of Surface Waves approach (MASW, Miller et al., 1999) was used at these sites to determine $V_{s}$ down to $30 \mathrm{~m}$ depth. Twenty four vertically oriented $4.5 \mathrm{~Hz}$ geophones were used for the MASW surveys. The dispersion of seismic surface waves (generated using stacked $5-10 \mathrm{~m}$ offset sledgehammer shots) is first determined using linear $f-k$ analysis. A model for the subsurface velocity $\left(V_{p}\right.$ and $\left.V_{s}\right)$ is subsequently estimated through a Rayleigh-wave based neighbourhood-algorithm (Wathelet 2008, Wathelet et al., 2004). In order to constrain the inversions for $V_{s}$, lithological layer models from the Single Onshore Borehole Index are used. To account for lateral heterogenerity, variation in the lithological layer-depths was permitted, with up to $\pm 2 \mathrm{~m}$ near the surface, increasing to $\pm 4 \mathrm{~m}$ at depths greater than $15 \mathrm{~m}$. In addition, an increase of $V_{s}$ with depth was imposed. At site $L 001$ the fundamental and first higher mode Rayleigh wave dispersion were jointly inverted, while at L003 and L009 only the fundamental mode was observed. The resulting shear-wave velocity profiles are shown in Figure 2.

Using the $\mathrm{V}_{\mathrm{s}}$ profiles, the travel time average velocity to depth $x$ is calculated:

$V_{s, x}=\frac{x}{\sum_{i=1}^{N} \frac{h_{i}}{V_{s, i}}}$

where $\mathrm{N}$ is the number of layers. The ith layer having thickness $h_{i}$ and shear-wave velocity $V_{s, i}$. An uncertainty on $V_{s 30}$ is obtained by taking the standard deviation of $V_{s 30}$ values over all possible $V_{s}$ profiles that fall within a site-specific dispersion-based misfit tolerance designed to fully encapsulate the observed dispersion. Since the inverted profiles typically have a smooth shape, a wider variety of possible profiles (greater misfit tolerance) is 
therefore required for more complex observed dispersion. Wathelet et al. (2008) define misfit as the root-mean-square of the difference in velocity (data minus modelled), normalised by the data uncertainty, over the range of observed dispersion frequencies. For site L001 the misfit tolerance was \pm 0.05 ; for $L 007 \pm 0.07$; and for L009 \pm 0.06 . We also determine $V_{s 30}$ through the Rayleigh wave phase velocity proxy. Foti et al. (2017) suggest that, at sites with shallow groundwater (as found around PNR), $V_{s 30}$ can be approximated by $V_{s 30}=V_{R, 40}$. Where $V_{R, 40}$ is the $40 \mathrm{~m}$ wavelength phase velocity. Table 1 summarises the $V_{s 30}$ values using the direct and dispersion-proxy approaches.

In addition to direct ( $\mathrm{V}_{\mathrm{s}}$ - or dispersion-based) measurements, $V_{s 30}$ can also be estimated from the fundamental resonance frequency of the site $\left(\mathrm{f}^{0}\right)$ along with bedrock depth $H_{b}$ and shearwave velocity $\left(V_{s b}\right)$, here assumed to be $1500 \mathrm{~m} / \mathrm{s}$ :

$V_{s 30}=\frac{30}{\frac{1}{4 f^{0}}+\frac{\max \left(0,30-H_{b}\right)}{V_{s b}}}$

(Hassani and Atkinson, 2016). We determine $f^{0}$ at all seismometer sites using the horizontalto-vertical (H/V) spectral ratios (HVSR) of ambient seismic noise (Table 2). Bedrock depth is taken from the BGS superficial deposits thickness model. Sites with alluvium or blown sand superficial geology show low variability in $\mathrm{V}_{\mathrm{s} 30}$, and a geometric mean $\mathrm{V}_{\mathrm{s} 30}=189 \mathrm{~m} / \mathrm{s}$ (Figure 3). Other geology types lead to wider variability, but the majority of sites have $V_{s 30}$ between $\sim 150$ and $300 \mathrm{~m} / \mathrm{s}$. The average $V_{\mathrm{s} 30}$ for peat sites is $248 \mathrm{~m} / \mathrm{s}$, while for till sites the average is $233 \mathrm{~m} / \mathrm{s}$, which correspond well to the MASW-based measurements (Table 1).

\section{Induced Events and Ground Motions}

A total of 14823 -component records from 57 events $\left(-0.8 \leq M_{\mathrm{L}} \leq 1.5\right)$ during hydraulic fracturing at PNR-1z (2018) and 3510 3-component records from 135 events (-1.7 $\leq M_{L} \leq 2.9$ ) during the second phase at well PNR-2 (2019) were initially visually screened for use. 758 of the PNR-1z records passed the initial inspection, while 947 of the PNR-2 records passed; a total of 1705 three-component records. The available dataset is uniform in terms of distance coverage between local magnitude -1 and 2.9 and epicentral distances 1 to $23 \mathrm{~km}$ (Figure 4). The smallest events $\left(M_{L}<-1\right)$ tend only to be recorded at very close distances.

\section{Usability of Ground Motion Recordings}

Signal-to-noise ratio (SNR) analysis was undertaken for all 1705 'visually acceptable' records. The frequency range ( $f_{\text {low }}$ to $f_{\text {high }}$ ) where the signal exceeds the noise level by a factor 3 was determined by comparing pre- or post-event noise Fourier amplitude spectra (FAS) with the signal FAS. For defining the range of usable periods ( $T_{\min }$ to $T_{\max }$ ) for response spectra and PGA we adopt the procedure developed for induced seismicity in the Groningen gas field, the Netherlands (Ntinalexis et al, 2019). For usable PGV we require $T_{\max }>0.1$ and $f_{\text {high }} / f_{\text {low }}>2$. 
It is notable that the events analysed here are dominated by high-frequency ( $f>5 \mathrm{~Hz}$ ) signals owing to their small size (mostly $M_{L}<1.5$ ). The usable period range is therefore limited, with significantly less usable data at T > $0.5 \mathrm{~s}$ (Figure 5). After usability checks, a total of $1007 \mathrm{high}$ quality records were available. For each record an assigned usable frequency and period limit is provided, and the record only used within these limits. The number of usable records, as used subsequently in our analyses, is reduced to 312 when limiting the magnitude range to $\mathrm{M}_{\mathrm{L}} \geq 0.25$ (Figure 4).

The BGS PNR earthquake catalogue defines earthquake size in terms of local magnitude $\left(\mathrm{M}_{\mathrm{L}}\right)$. These values must be converted (Dost et al., 2018, 2019) for compatibility with GMPEs available for induced seismicity, which use moment magnitude, M. For the smallest events, we assume that:

$$
\mathbf{M}=\frac{2}{3} M_{L}+0.833 \quad\left(\mathrm{M}_{\mathrm{L}}<1.5\right) \quad \text { (Edwards et al., 2015), }
$$

which is based on analysis of induced geothermal events at St Gallen, Switzerland, and on the theoretical model of Deichmann (2017). Equation 3 was found to provide very similar predictions to an empirical model developed by the operator (Cuadrilla Resources 2019b), who used a selection of the 2018-phase events to show:

$$
\mathbf{M}=0.655 M_{L}+0.897 \quad\left(-0.8 \leq M_{L} \leq 1.5\right)
$$

For larger events, we adopt the European model of Grünthal et al. (2009):

$$
\mathbf{M}=0.0376 M_{L}^{2}+0.646 M_{L}+0.53 \quad\left(\mathrm{M}_{\mathrm{L}} \geq 2.5\right)
$$

with linear interpolation between Equations 3 and 5 from $1.5 \leq M_{L} \leq 2.5$ to ensure there are no sudden jumps in the conversion (Figure 6). We acknowledge that there are uncertainties in the conversion equation particularly for small magnitudes, where the consistency between $\mathbf{M}$ and $M_{L}$ is expected to diverge (Deichmann, 2017). We are aware, for instance, that $\mathbf{M}$ catalogued by the operator from downhole data (generally $M_{L}<0$ ) are systematically lower (by approximately half a magnitude unit) than those at the surface (Mancini et al., 2019). The source of these downhole-derived moment magnitudes is a 'black box' solution provided by a subcontractor to the operator (pers. comm. Cuadrilla Resources). Since there are numerous assumptions that are required to compute moment magnitudes from small earthquakes we therefore treat these with caution. The use of the selected relationship is justified given the fact that our aim is to investigate the motions at the surface, the fact that the $M$ versus. $M_{L}$ is consistent with other empirical and theoretical models. Nevertheless, future work may wish to consider this epistemic uncertainty.

\section{Assessment of Predictive Models}

Recorded ground motions for events with $\mathbf{M}>1\left(M_{L}>0.25\right)$ at PNR have been compared to the predictions from GMPEs of Atkinson (2015) and Douglas et al. (2013) with the aim of selecting a model for subsequent adjustment using the referenced empirical approach (Bommer et al, 2006; Atkinson, 2008). An example for PGV is shown for the largest events 
during the $2018\left(M_{L} 1.5\right)$ and $2019\left(M_{L}\right.$ 2.9) hydraulic fracturing phases in Figure 7. The reason for restricting our analyses to the 'larger' $\left(M \geq 1\right.$, or $\left.M_{L}>0.25\right)$ of the recorded events is because (i) the data at $\mathbf{M}<1$ are more likely to be biased high (i.e. only the strongest records are recorded over the baseline noise); (ii) the functional form of the GMPEs may not be able to accommodate a wider range of $\mathbf{M}$ (Douglas and Jousset, 2011) and (iii) $\mathbf{M}<1$ events are clearly irrelevant from a seismic risk perspective. Site specific $V_{s 30}$ is used in the assessment with $\mathrm{V}_{\mathrm{s} 30}=190 \mathrm{~m} / \mathrm{s}$ for sites on blown sand deposits, $230 \mathrm{~m} / \mathrm{s}$ for till, and 250 for alluvium and peat. The values are log-averages of $\mathrm{V}_{\mathrm{s} 30}$ estimated from measured fundamental frequency of resonance and bedrock depth at each of the 26 seismometer sites (Equation 2, Figure 3), grouped by superficial geology.

The empirical GMPE of Douglas et al. (2013), developed specifically for geothermal induced seismicity, was first tested for its applicability to the PNR dataset. Multiple empirical models were proposed by Douglas et al. (2013). We use their 'Model 1' that uses a $V_{s 30}=1100 \mathrm{~m} / \mathrm{s}$ reference site, and modified here for local site-specific $\mathrm{V}_{\mathrm{s} 30}$ (as detailed previously) using the Boore et al. (2014) site amplification model. The Douglas et al. (2013) model was developed using data with $\mathbf{M} \geq 1$ and $R<30 \mathrm{~km}$ and therefore directly applicable to the subset $(\mathbf{M} \geq 1)$ of PNR data used here. The model has large aleatory uncertainties, owing to the variety of data sources and potentially poor metadata quality. On average, it was found to adequately predict (bias within $10 \%$ ) $0.03-0.5$ s PSA across the range of model-valid distance and magnitude. On the other hand, PGA, PGV and 0.02 PSA were systematically overpredicted, apart from for the largest events $(M\llcorner 1.5,2.1,2.9)$. A trend of increasing over-prediction with decreasing magnitude was apparent across all ordinates, but particularly for short period motions (0.02 s PSA, PGA) and PGV. This leads to significant overprediction at the lower end of the model's validity, and where most of our data lie (i.e. for $1 \leq \mathbf{M}<1.5$ ) with bias factors of 1.9 for PGV and 1.2 for $0.02 \mathrm{~s}$ PSA and PGA. This is not particularly surprising given the significant regional differences observed by Douglas et al. (2013). The fact that predictions of PGA and PGV were poor within the model-valid magnitude and distance range therefore led us to rule out this model as a basis for the referenced empirical approach. The justification for this is that PGA and PGV play a central role in subsequent estimation of macroseismic intensity and risk in this study and, in addition, PGV is typically used in regulation (BSI 1993). Furthermore, the functional form of the GMPE includes only linear magnitude scaling and does not fully account for magnitude-distance-dependent saturation of ground motions. This will present problems when predictions are required for not only the small recorded events, but also larger hypothetical (risk-focussed) scenarios.

Notably, our decision not to use the Douglas et al. (2013) model as the basis for calibration of a PNR specific GMPE is in contrast to Cremen et al. (2020). Their calibration was based on very near-field records from PNR and New Ollerton, UK, at distances less than $6 \mathrm{~km}$. It does not consider site-specific or non-linear effects but rather uses the 'unknown' (or average) site prediction provided by Douglas et al. (2013). Comparing the Cremen et al. (2020) GMPE with 
the data recorded at PNR (Figure 8) we observe a good fit at short distances and low magnitudes ( $M_{L}<1 ; R<10 \mathrm{~km}$ ) but increasingly significant underestimation of motions for records with magnitudes and distances outside this range (although it is noted that their model is strictly only calibrated to $6 \mathrm{~km}$ ). We believe the underprediction is likely due to the overly-simple functional form of the Douglas et al. (2013) GMPE, which, as previously discussed, does not include quadratic magnitude-scaling or magnitude-dependence of distance-scaling that would make it suitable for predictions over a broad range of magnitude. Consequently, the Douglas et al. (2013) model has limited flexibility for calibration to local data, particularly while maintaining predictions for motions at larger magnitude (Douglas and Jousset, 2011).

The GMPE of Atkinson (2015) was developed for instances of induced seismicity. It is based on the NGA-West2 dataset (Ancheta et al., 2014) and comprises of records of M $3-6$ earthquakes. The majority of smaller magnitude events in the NGA-West2 dataset are Californian tectonic earthquakes and are not necessarily shallow. However, records used by Atkinson (2015) were limited to those within $40 \mathrm{~km}$ of the hypocentre to focus the model on near-source motions. Of some concern is that the lower magnitude limit of data used to derive the GMPE is above the magnitude range available in our dataset. However, given the limited selection of candidate GMPEs for induced seismicity we evaluate the model to test the extrapolation potential of the model beyond its strict validity. Atkinson (2015) proposed two alternative models for near-source distance saturation for large magnitude events using $h_{\text {eff }}=\max \left(1,10^{-1.72+0.43 M}\right)$ and $h_{\text {eff }}=\max \left(1,10^{-0.28+0.19 M}\right)$. We use the latter, as suggested by the author in a subsequent study (Atkinson, 2020). The GMPE predictions are natively made for a reference $V_{s 30}=760 \mathrm{~m} / \mathrm{s}$, with no $V_{s 30}$ variable in the predictive equation. We therefore use the site response model of Boore et al. (2014) for application to the low $V_{s 30}(\sim 200-300 \mathrm{~m} / \mathrm{s})$ values observed at PNR.

We find that, despite being applied below the magnitude range used in its derivation, the predictions of Atkinson (2015) are generally satisfactory at distances greater than a few $\mathrm{km}$ and $M_{L}>0.5$ (Figure 9). PGA and, to a lesser extent, PGV residuals highlight that the model systematically underpredicts mid- to short period motions in the very near-field $(R<5 \mathrm{~km})$, as previously shown by Edwards et al. (2019) and Cremen et al. (2020). In fact, the scatter of residuals for PGA and PGV suggests the sigma value in the Atkinson (2015) model is necessary to capture the range of motions observed at short distances $\left(R_{e p i}<5 \mathrm{~km}\right)$, but may significantly overestimate variability at longer distances $\left(R_{\text {epi }}>5 \mathrm{~km}\right)$. Mid- to long-period motions $(T \geq 0.3$ s) are predicted with minimal average bias across the range of magnitude and distance available in the observed data (with no apparent trends) and exhibit a significantly lower variability than in the Atkinson (2015) model. It is noted that the choice of $h_{\text {eff }}$ model for Atkinson (2015) does not have an impact at these near-field prediction's low magnitudes (yielding a $0.01 \mathrm{~km}$ difference at $\mathrm{M} 1.5$ ). It could be argued that the rapid decay of near-field motions is confined to the majority of small $\left(M_{L}<1.5\right)$ events in the dataset which would then 
present negligible influence on seismic risk, however, residuals for the larger of the earthquakes ( $M_{\llcorner} 2.1$ and 2.9) show the same behaviour (Figure 10).

Bommer et al. (2006) and Atkinson (2008) showed that improvements in local ground motion prediction can be achieved using the referenced empirical approach. A base GMPE (here Atkinson, 2015) is calibrated to recordings made in the region of interest. We undertake the calibration of the Atkinson (2015) GMPE using a mixed-effects regression. We initially fit 'unadjusted' residuals (i.e. difference between logarithms of observed and predicted motions, as shown in Figure 9) with parametric form as per the original GMPE:

$X=\Delta c_{0}+\Delta c_{1} \mathbf{M}+\Delta c_{2} \mathbf{M}^{2}+\Delta c_{3} \log _{10} R+B_{e}+W_{S}$

With $X$ the $\left(\log _{10}\right)$ residual for a given spectral ordinate, $\mathbf{M}$ the moment magnitude and $\mathrm{R}$, an effective distance, as defined in Atkinson (2015) as:

$$
R=\sqrt{R_{\text {hyp }}^{2}+\max \left(1,10^{-0.28+0.19 M}\right)^{2}}
$$

$B_{e}$ are random effects for the events, with prior belonging to a normal distribution defined by $\mathcal{N}(0, \tau)$ and $W_{S}$ are station-specific random effects with prior defined by $\mathcal{N}(0, \phi)$. For induced seismicity applications, as here, we are constrained by the limited magnitude range of events. A constraint is therefore applied that the adjusted GMPE should converge to the original for $\mathbf{M} \geq 4.5$ at $\mathrm{R}_{\text {hyp }}=20 \mathrm{~km}$, roughly the mid-point of the dataset used in its derivation. The adjusted ground motion amplitudes, $Y_{A 15 c}$, are given by: 


$$
\begin{aligned}
& \log _{10} Y_{A 15 c}=d_{0}+d_{1} \mathbf{M}+d_{2} \mathbf{M}^{2}+d_{3} \log _{10} R \quad \mathbf{M}<3 \\
& \log _{10} Y_{A 15 c}=p_{0}+p_{1} \mathbf{M}+p_{2} \mathbf{M}^{2}+p_{3} \log _{10} R \quad 3 \leq \mathbf{M}<4.5 \\
& \log _{10} Y_{A 15 c}=Y_{A 15}=c_{0}+c_{1} \mathbf{M}+c_{2} \mathbf{M}^{2}+c_{3} \log _{10} R \quad \mathbf{M} \geq 4.5
\end{aligned}
$$

With $c_{i}$ the original coefficients (Atkinson, 2015), $d_{i}$ are the calibrated coefficients (Table 3 ) given by $c_{i}+\Delta c_{i}$ (with $\Delta c_{i}$ according to Equation 6 , Table 4 ) and $p_{i}$ are linearly interpolated with magnitude between the $c_{i}$ and $d_{i}$ (i.e. $p_{i}=c_{i}+\frac{\mathbf{M}-4.5}{3-4.5} \Delta c_{i}$ ). The calibrated model is shown along with the original GMPE in Figure 11. The most obvious difference is significantly higher near-field short period motions in the calibrated GMPE, a feature already noticed in the data (Figures 9, 10). The constraint applied in the regression to limit the modification of the GMPE at large magnitudes is evident in Figure 11, with predictions almost identical to the original GMPE already by $M=4$.

Figure 12 shows the residual misfit of the calibrated GMPE (as Figure 9 for the original). The behaviour is greatly improved, with centred residuals across the range of distances ( 0 to 23 $\mathrm{km}$ ) and magnitudes ( $M_{\llcorner} 0.25$ to 2.9). A slight trend in residuals may remain (albeit significantly reduced) at the shortest distances $(R<2 \mathrm{~km})$, but in order to accommodate this a change of functional form would be required, which we consider to be unjustified given the uncertainties of extrapolating this behaviour beyond the observed magnitude range.

Ground motion variability observed the PNR data (Table 4) is dominated by within-event terms, with between-event variability $(\tau)$ very small and consistent with the 'single source' seismicity (Lin et al., 2011; Atkinson, 2006). While the number of events used here is too small to robustly determine $\tau$, we can nevertheless use this as justification to reduce the between-event variability used in subsequent applications of the GMPE at PNR. Indeed, other studies based on single-source datasets (Lin et al., 2011, Rodriguez-Marek et al., 2013) suggest a $\sim 60 \%$ reduction in $\tau$. To strike a balance between conservatism and acknowledging the unique single-source scenario at PNR we implement variability according to the values presented by Atkinson (2015). We reduce $\tau$ by a factor of 0.67 (a 33\% reduction), and retain the original values of $\phi$ (Table 3).

\section{Assessment of Potential Impact of Future Scenarios}

We define five earthquake scenarios (from $M_{L}=2.5$ to 4.5 , inclusive) that are considered possible (but not necessarily likely) at PNR. In addition, $M_{L} 2.1$ and 2.9 scenarios are investigated, allowing direct comparison with the largest events which have already occurred and therefore empirical evidence of macrosesimic effects, such as building damage.

Ground motion fields are calculated using the geology-dependent spatially-variable $\mathrm{V}_{\mathrm{s} 30}$, with $\mathrm{V}_{\mathrm{s} 30}=190 \mathrm{~m} / \mathrm{s}$ for blown sand deposits, $230 \mathrm{~m} / \mathrm{s}$ for till, and 250 for alluvium and peat (as defined previously for the residual analyses). These average $\mathrm{V}_{\mathrm{s} 30}$ values are assigned to the risk calculation according to the BGS superficial geology map, which has been discretised 
according to modal geology-type within a $1 \times 1 \mathrm{~km}$ gridding interval. The non-linear site amplification model of Boore et al. (2014) is implemented to account for the presence of low velocity soils. Median levels of macroseismic intensity (equivalent to EMS-98) are calculated following Caprio et al. (2015) using predicted median and 84th-percentile values of PGV for the $M_{L} 2.9$ (Figure 13) and hypothetical $M_{L} 4.5$ events (Figure 14), resulting in epicentral intensities of IV and VI to VII, respectively. We note that that equations available for determining macroseismic intensity from ground motion intensities (PGA, PGV, etc.) are invariably based on tectonic earthquakes. Applying these conversion equations to motions from induced seismicity (typically smaller magnitude events, with short-duration highfrequency acceleration time-histories) may therefore introduce a bias in the conversion (Lesueur et al., 2013). Nevertheless, PGV is generally found to be the most reliable ground motion metric for predicting macroseismic intensity over a wide range of scenarios (e.g., Wald et al., 1999; Worden et al., 2012) owing to it being related to a range of 'mid-frequency' motions that scale with magnitude.

Caprio et al. (2015) further suggest almost a unit standard deviation on the intensity for a given PGV scenario. This means that for the highest levels of motion considered here (84thpercentile PGV), EMS-98 macroseismic intensity for single localities could feasibly reach $V$ and VIII near the epicentre for the $M_{\llcorner} 2.9$ and 4.5 events, respectively. However, we note that only $16 \%$ of the spatially distributed motions are expected to ever exceed the 84th-percentile prediction of PGV, and of these, only $16 \%$ would be considered to potentially reach or exceed the +1 unit standard deviation in EMS-98 intensity (a combined probability of $2.6 \%$ ). Due to the rural nature of the epicentral region around PNR it would be highly unlikely for these 'point-localities' experiencing low-probability PGV and PGV-based intensity to also correspond to building locations.

\section{Risk Analysis}

A grid extending $7 \mathrm{~km}$ to the west, $6 \mathrm{~km}$ to the south and $9 \mathrm{~km}$ to both the north and east of the PNR well is considered in the following analyses. The grid consists of 240 cells, each of 1 $\mathrm{km}^{2}$ (Figure 15). The extent of the grid has been defined based on the boundary of macroseismic intensity $V$ in the maps calculated for a $M_{L} 4.5$ event in a preliminary state of this study Edwards et al. (2019) together with the built-up area in the region (Figure 15).

\section{Ground Motion fields}

Using the calibrated GMPE and revised variability model (Table 3), 500 random ground motion fields have been calculated for each of the seven individual scenarios: earthquake magnitudes ( $M_{L} 2.5$ to 4.5 at 0.5 unit intervals in addition to events with $M_{L} 2.1$ and 2.9). All scenario events are simulated with epicentre at the centroid of the PNR-1z seismic cloud $(53.78754 \mathrm{~N}$, $2.96477 \mathrm{~W}$ ) and at $2.35 \mathrm{~km}$ depth, as defined by the BGS earthquake catalogue. This location is less than $190 \mathrm{~m}$ from the centroid of BGS catalogued epicentres at the adjacent well PNR-2 and only $80 \mathrm{~m}$ away from the location of the $M_{L} 2.9$ event, distances well within the 
uncertainty of event locations and irrelevant for subsequent hazard and risk calculations. We note that there is an uncertainty associated with the location of future events - but the analysis performed here is not intended to be fully probabilistic, but rather demonstrate likely hypothetical scenarios. Note that for $T=2 \mathrm{~s}$ no calibration was undertaken (due to a lack of recorded data at $T=2 \mathrm{~s}$ ), therefore the original predictions of Atkinson (2015) are used. Multiple risk calculations are performed for each of these spatially-correlated motions. In practice, each scenario event has a between-event term randomly selected (from a lognormal distribution with standard deviation $\tau$ from Table 3 ). Single-scenario variability is then applied through random sampling from a lognormal distribution with standard deviation $\phi$, conditioned on the spatial correlation model of Jayaram and Baker (2009). As noted earlier, $\tau$ and $\phi$ (Table 3) are both taken from the original model of Atkinson (2015), with $\tau$ reduced by a factor 0.67 to account for the 'single source zone' seismicity.

\section{Inventory of Exposed Structures}

Open datasets have been compiled to produce an inventory of the exposed structures and population within the region of the PNR site. OpenStreetMap building footprints were used to estimate the total number of buildings in each grid cell and the CORINE Land Cover data is used to estimate the number of buildings in each grid cell that fall within urban, rural, industrial and sports/leisure land use classes. A field survey was undertaken to estimate the number and distribution of different building classes across the study area. The buildings fall into four distinct classes: detached unreinforced masonry housing, terraced unreinforced masonry housing, mobile homes and light steel frame buildings. A judgment-based mapping scheme, considering available information from the field survey and online data resources, is implemented to assign a percentage of each building type based on the land use class (Table 5). By combining the mapping scheme with the gridded layer of building numbers in each land use class, the number of buildings of each building class in each grid cell is estimated. The average age of the buildings across the whole region was taken from the CDRC Dwelling Age dataset for building age classification.

We assume that $15 \%$ of the brick masonry buildings are constructed pre-1920 based on the dwelling age data, and that they all have brick chimneys. The remaining brick masonry buildings are considered to be post-1920, with $50 \%$ of these assumed to have brick chimneys. There are a total of 56,420 buildings in the exposure model of which 31,135 are masonry buildings with chimneys (Figure 16).

\section{Risk Calculation}

We use numerical models and corresponding capacity curves for detached and terraced masonry houses and light steel frame buildings from Arup (2017; 2019) and Mosayk (2017). These models have been developed as part of the probabilistic seismic risk assessment for the Groningen gas field (van Elk et al., 2019) and are considered suitable here due to the similarity in style and construction to buildings around PNR. The capacity curve for mobile 
homes is instead taken from HAZUS (FEMA 2004). In order to model chimney damage, the data collected from the study of Taig and Pickup (2016) were used. Following an extensive review of chimney damage in past earthquakes, they proposed lower and upper bound fragility functions for buildings constructed before and after 1920. Subsequently, Taig (2018) concluded that the fragility assumptions substantially overstated the likelihood of failures at low levels of PGA. In our analyses, the lower bound values are therefore taken as the "best estimate' and a lognormal distribution fit to the data points of PGA versus probability of failure (giving median PGA values of $0.585 \mathrm{~g}$ and $0.765 \mathrm{~g}$ with dispersion of 0.62 and 0.52 for pre- and post-1920 buildings, respectively). Furthermore, we define a minimum level of PGA $(0.08 \mathrm{~g})$ below which chimney collapse is not considered. This value has been assumed based on the maximum PGA that has been recorded at PNR $(0.08 \mathrm{~g})$, together with the fact that no chimneys have collapsed to date.

Fragility functions for the buildings are developed following Crowley et al. (2019a). First, simplified single-degree-of-freedom (SDOF) structural models with backbone curves based on the defined capacity curves are subjected to nonlinear dynamic analysis. Crowley et al. (2019) selected acceleration time-histories that were consistent with the levels of induced seismic hazard in the Groningen field for 5 levels of ground motion that varied between PGA values of $0.03 \mathrm{~g}$ and $1 \mathrm{~g}$. These same ground motions have been used herein. With additional time and resources, one would ideally undertake a probabilistic seismic hazard analysis (PSHA) at the PNR site and then select records that are consistent with this hazard (following disaggregation of the hazard to understand the magnitude, distance, epsilon and duration of the events contributing most to the hazard at different levels of intensity) following, for example, the methods outlined in Bradley (2010) and Baker and Lee (2018). However, as a PSHA is not currently available for the site, the same records from the Groningen gas field study have been employed given that they do reflect the characteristics of induced seismicity. It is noted that the duration of the employed records is likely to be longer than expected for the magnitude of the events considered and there may be differences in the frequency content. This may lead to higher estimations of damage than actually expected.

The peak displacement response of each structure is obtained along with a bi-linear model fit to the data (Figure 17). The defining spectral ordinate for each structural type is selected as that with the lowest dispersion in SA versus SD (i.e. the most efficient), and an implicit assumption is taken that this intensity measure is also sufficient given that recent studies have shown that the higher the efficiency of the intensity measure, the higher the sufficiency (e.g. Bradley et al., 2010). PGV was also considered as an alternative intensity measure but it was not found to have a higher efficiency than the other spectral ordinates considered. Displacement thresholds for structural damage states in masonry structures (DS1 - 4 according to the EMS damage scale) have been obtained from the results of experimental testing (Graziotti et al., 2019; Borzi et al., 2008) and, for the steel-frame buildings and mobile homes, from HAZUS (FEMA 2004). The probability of reaching or exceeding these levels of 
displacement (Figure 18) is finally determined using the median displacement response (Figure 17) for a given SA, together with its aleatory variability. For further details refer to Crowley et al. (2017; 2019b). A recent study undertaken by Chase et al. (2019) has investigated the issue of damage accumulation for the specific case of sequences of induced earthquakes. They show that the fragility of timber-frame buildings was not influenced by sequences of low magnitude events, as the damage was typically light enough that it did not alter the capacity of the building to withstand the next event in the sequence. It follows that this may also apply to the generally stiffer masonry structures that dominate our study region. Damage accumulation is therefore not considered in the present study, but more work is required on the potential for this due to both prior earthquakes and foundation settlement.

The 'Scenario Damage Calculator' of the OpenQuake-engine (Silva et al., 2014) has been used to calculate the damage distribution for each scenario-based ground-motion field. The spatial distribution of the mean and standard deviation of the probability of reaching each damage state (DS1, DS2, DS3, DS4 and chimney collapse) for each magnitude scenario and building class is then determined (Figures 19, 20, Table 6). Figure 21 compares the box and whisker plots showing the total percentage of buildings in each damage state for the scenario events with $M_{L}=2.9$ and $M_{L}=4.5$. These plots illustrate the large impact of ground motion variability on the mean percentage of damaged buildings, in particular for the low magnitude event.

\section{Comparison with Observed Damage}

The only publicly available damage data that is currently available for the $M\llcorner 2.9$ event comes from BGS 'did-you-feel-it?' data. This consists of self-reported damage from the occupants of buildings within the PNR region. A total of 2266 responses were submitted for this event. There are significant caveats to consider in using this data: (i) damage reports are not provided by structural engineers; (ii) heightened emotions can influence the verity of the responses; (iii) multiple damage entries may exist for the same structure.

The 'did-you-feel-it?' responses for each building have been mapped to DS0, DS1 and DS2 using the EMS-98 damage scale (Grünthal et al., 1998). DS1 has been defined where any of the following were reported: small cracks in plaster, small amounts of falling plaster, or falling stones. DS2 has been defined for: large cracks in plaster, a large amount of fallen plaster, or large cracks in walls. Note that the somewhat ambiguous descriptors are taken directly from the 'did-you-feel-it?' responses and therefore present the only level of differentiation between damage states available to us. Furthermore, direct mapping of individual 'damage features' does not account for the extent of damage and is therefore likely to provide conservative estimates of the building's damage state. Noteworthy here is that one report of a 'collapsed wall' and one of a 'collapsed house wall' were received, but from the accompanying damage descriptions it was clear that these were not wall collapses and were therefore not considered as such. 
The total number of damage reports indicating DS1 according to the 'did-you-feel-it?' data is 97. A further 50 reports are classified as indicating DS2. No chimneys were reported to have collapsed. The modelling results show a good similarity, with a mean of 75 buildings with DS1, 10 buildings with DS2 and $<1$ building with chimney collapse (Table 6 ) only slightly lower than the empirical data. For the median values of modelled damage (17 at DS1 and 0 at DS2) the difference is more significant, but as shown in Figure 21, this is due to the skewed distribution of the numbers of buildings at each damage state. The mean values are more strongly influenced by a limited number of high-damage scenarios that lie in the long tails of the distribution. We therefore consider the median to be a better representation of the typical number of buildings with a given damage state, while the mean better represents the influence of outlier scenarios. Furthermore, the somewhat higher reported values of damage could be both due to the unreliable self-reporting of damage, possible duplications of reports for a single building, and the conservative mapping to the EMS-98 damage scale.

Due to data protection regulations, specific localities were not provided with individual 'didyou-feel-it?' responses. Instead, postcode districts were provided. Each postcode district is broadly population based, so larger postcode districts indicate more sparsely populated areas. For the purpose of comparison, the damage results have been mapped into these postcode districts (Figures 22, 23). It should be noted that this is an inherently unfair comparison: the 'did-you-feel-it?' reports from a single earthquake are certainly not a complete dataset and are also likely biased (as noted previously). The 'did-you-feel-it?' reports are also not uniformly sampled across the region. Furthermore, the modelled damage map represents the mean of a probability density function of the number of damaged buildings at a given damage state (Figure 21) within each postcode district. Therefore, comparison with the average over many $M_{\llcorner} 2.9$ earthquakes would be a fairer comparison. Nevertheless, a comparison of the predicted damage maps with those based on the 'did-youfeel-it?' data is undertaken to provide a first order assessment. The data shows that the modelled damage is more concentrated in the built-up areas west of the PNR site, whereas the 'did-you-feel-it?' data indicates highest damage in the postal district to the south of the PNR site. A possible explanation for this could be site amplification effects, since the area to the south includes areas lying in the flood plain of the River Ribble, and therefore located on alluvial deposits. Our analyses indicated similar $\mathrm{V}_{\mathrm{s} 30}$ and $\mathrm{HVSR}$-based $\mathrm{f}^{0}$ in this region to other districts, so the exact cause is unclear. Further site investigation using direct-measurements (e.g. MASW) in this region may help understand if stronger site effects are present here.

Comparing the modelled damage for larger events with observed damage in past events (see Edwards et al., 2019 for further details), we note that events that occurred in Basel, Switzerland (2006, M3.2, depth $5 \mathrm{~km}$ ) and Huizinge, Netherlands (2012, M3.5, depth $3 \mathrm{~km}$ ) both led to a much larger number of buildings with DS1 (approx. 2000) than observed in our model. However, there is suggestion that pre-existing DS1 damage was present in these 
buildings due to lack of maintenance and settlement of foundations (see e.g. Bommer et al., 2015). Conversely, damage caused by the Darmstadt event (2014, M3.6, depth $5 \mathrm{~km}$ ) had reported levels of DS1-2 and chimney collapse which are slightly lower than the estimates made here for the $M_{L} 3.5$ scenario. The Folkestone (UK) (2007, M4.0, depth $5.3 \mathrm{~km}$ ) earthquake damaged approximately 1000 buildings (DS1-2) and a number of chimneys. A larger degree of damage has been estimated for a hypothetical $\mathrm{M}\llcorner 4.0$ event at PNR. However, this is due at least in part to the significantly greater exposure, with earthquakes being in close proximity to the city of Blackpool along with the soft soils present in the coastal region. While a comparison that directly accounts for exposure would therefore be highly informative, the data for such a comparison are, unfortunately, not uniformly available.

\section{Discussion}

A comprehensive analysis of recorded ground motions, development of a structural inventory and site characterisation at PNR has allowed us to model the expected ground motion, macroseismic intensity and damage for a range of earthquake scenarios. Initial work by Edwards et al. (2019), undertaken prior to the larger events of 2019, was focused on theoretical scenarios. The recent $M_{L} 2.9$ has now provided opportunity to compare observations with these models. In terms of damage, the predictions are seen to be consistent overall, both in total number and, albeit to a much lesser extent, spatial distribution. This supports the usefulness of a pseudo-probabilistic risk assessment, as implemented herein and allows decisions to be made on future production with awareness of the associated seismic risk. We acknowledge that the approach presented would benefit from extension to a full probabilistic hazard and risk assessment and could be implemented within a real-time operational forecasting, such as proposed for 'nuisance felt ground motions' by Cremen and Werner (2020). However, such analyses are significantly more costly. Our proposal would therefore be to undertake full probabilistic analysis only after a scenario-based analyses, as shown here, presents acceptable risk.

Site amplification clearly plays an important role in seismic hazard and risk, and this is a particular issue at PNR given the low velocity superficial geology. The geology-based proxies implemented in this study make use of available information: namely surface and bedrock geology type and bedrock depth. However, they cannot explain some of the damage distribution that may otherwise be caused by local variations in site effects. In order to understand the detailed spatial distribution of damage, direct measurements of Vs are required on a much larger scale. This information may also be useful in making decisions on siting of wells away from regions of very low $V_{s 30}$ and associated strong site amplification. One element that has not been addressed in our analysis is the impact of pre-existing building weakness. It has been observed that buildings can behave non-linearly throughout and after sequences of repeated dynamic loading (Astorga et al., 2018). On the other hand, for the specific case of induced seismicity, Chase et al. (2019) found no evidence of damage accumulation to light-frame structures. Nevertheless, we consider that structural settlement 
due to thick sedimentary deposits of sand and alluvium may have weakened the structural resistance of some buildings and may lead to bias in the number of damaged buildings in particular areas.

Records of seismicity, at much lower levels than usually used $(\mathbf{M}>1)$ have proved invaluable in testing and calibrating GMPEs for use at PNR. Earthquake detection and localization require a dense network near to and around the earthquake epicenters. However, calibrating GMPES requires the consideration of ground motion attenuation to distances up to $20 \mathrm{~km}$ or even more for the largest events. At PNR the more distant records have been provided independently by the BGS and UoL, with the operator concentrating on the epicentral region to optimise the minimum detection threshold. A similar level of seismic monitoring by the operator (or responsible agent) both within and outside the epicentral zone is an important feature to maintain for future projects.

The macroseismic intensity of the $M\llcorner 2.9$ event is somewhat contentious. Originally assigned as VI by the BGS based on 'did-you-feel-it?' reports, this is at the top end of intensities observed for such small events. Considering observations and region-wide predictions of PGV we expect epicentral intensities of IV for an event of this size, which is consistent with the range of intensities assigned to previous shallow $\mathrm{M}_{\mathrm{L}} 2.9$ events in the UK (III to V). Caprio et al. (2015) define PGV values of $0.54,2.3$ and $5.5 \mathrm{~cm} / \mathrm{s}$ using their global model (their Equation 2) for intensity IV, V and VI, respectively. The largest PGV at PNR was $0.9 \mathrm{~cm} / \mathrm{s}$, observed very close to the epicentre $\left(\mathrm{M}_{\mathrm{L}}=2.9 ; R_{\mathrm{epi}}=1.9 \mathrm{~km}\right)$. Extrapolating PGV using the adjusted GMPE (Equation 8) from $1.9 \mathrm{~km}$ to zero epicentral distance we would expect a $32 \%$ increase. Therefore, the maximum observed PGV could increase to $1.2 \mathrm{~cm} / \mathrm{s}$. According to Caprio et al. (2015) this would clearly fall short of intensity V, never mind intensity VI. However, the authors also propose roughly one-unit for the standard deviation on their predicted intensities, which means that there is a small but non-zero (2.2\%) likelihood that an intensity of $V$ (at plus 2 sigma) is possible from such an event.

Ultimately, intensity $\mathrm{V}$ and $\mathrm{VI}$ should be defined by occurrence of physical damage according the EMS-98 classification. In our modelling of the $M_{L} 2.9$ around $1 \%$ buildings within $1 \mathrm{~km}$ of the epicenter were assigned DS1 damage, far below the EMS-98 definition of 'many' buildings required to assign intensity VI. Instead, intensity V seems appropriate, if damage is indeed verified. Intensity $\mathrm{V}$, while not immediately apparent in the 'summary descriptions' of intensity, includes ' $f e w$ ' (up to $10-20 \%$ ) buildings with minor cosmetic damage (Grünthal et al., 1998). This highlights the disadvantage of intensity assignment based on 'did-you-feelit?' reports alone. They are inherently positively biased: the public are, understandably, far more likely to report 'felt' effects than not, and this is exacerbated as the 'significance' of the felt event increases.

\section{Conclusions}


A risk analysis associated to induced seismicity has been undertaken for the shale gas site at Preston New Road, near Blackpool, UK. We have carefully defined usable ground motion records from events $\left(M_{L}>0.25\right)$ that would typically be unused in risk analyses. These records have been used to calibrate a GMPE using the referenced empirical approach. Site effects are accounted for using a non-linear geology-dependent model that accounts for the very low shear wave velocity of near surface sediments around PNR. These sedimentary deposits contribute to the higher than normal levels of motion (and subsequently damage) that might be expected from moderate earthquakes.

We found that existing GMPEs for induced seismicity (Atkinson, 2015 and Douglas et al., 2013) were not unbiased in their published form for predicting ground motions at the PNR site. This highlights the necessity to have locally calibrated application-specific models that account for observed data, as proposed by Bommer et al. (2016). The approach presented here facilitated the calibration of model coefficients such that, to the extent permitted by the functional form, the predictions were unbiased in the magnitude and distance range available, while retaining the original model predictions at larger magnitudes and distances. We nevertheless find refinement to the functional form would be necessary to account for the very steep decay of ground motions in the very near field $\left(R_{\text {epi }}<3 \mathrm{~km}\right)$.

The risk analysis, undertaken using multiple realisations of ground motion for several scenario events, provides damage estimates (with a mean of 75 buildings at DS1 and 10 as DS2) that are comparable to those observed for the $\mathrm{M}\llcorner 2.9$ event, although caveats must be considered when using 'did-you-feel-it?' damage data. An increase in the magnitude of induced events beyond the largest experienced to date, even by a relatively moderate degree, will clearly lead to an increase the quantity and severity of damaged buildings. Specifically, we estimated not insignificant numbers (median $\geq 50$ ) of buildings at DS2 for a $M_{L} 3.5$ event, DS3 for a $M L$ 4.0 event and DS4 for a $M_{L} 4.5$ event, respectively. The soft soils, shallow earthquake focal depths and proximity to the city of Blackpool clearly, therefore, exacerbate the effects of what may otherwise be considered minor events.

\section{Data and Resources}

Map data copyrighted OpenStreetMap contributors and available from https://www.openstreetmap.org (last accessed November 2020). Open source datasets used in this project are: CORINE Land Cover (2018) [@ European Union, Copernicus Land Monitoring Service 2018, European Environment Agency (EEA)]; and CDRC Dwelling Age map and dataset (maps.cdrc.ac.uk, last accessed November 2020). Waveform and 'did-you-feel-it' data are available on request from the British Geological Survey (BGS and operator data) and University of Liverpool (UoL data). UK bedrock depth, geology maps and lithological profiles from the Single Onshore Borehole Index are available from the BGS at www.bgs.ac.uk (last accessed November 2020). OpenQuake is available at www.globalquakemodel.org (last accessed November 2020). 


\section{Acknowledgements}

We thank the Oil and Gas Authority for funding this study and providing or facilitating the provision of various datasets used herein. We are also grateful for the funding from EU project URBASIS (grant number 813137) which has supported this project. We extend our thanks to the British Geological Survey, in particular Richard Luckett and Brian Baptie, who provided data for the surface seismometers operated by both the BGS and by Cuadrilla Resources. We would also like to thank Francesco Cavalieri for support in the implementation of piecewise linear regression for the fragility functions. Finally, we thank Gemma Cremen, an anonymous reviewer, and associate editor Luis Dalguer for their thorough review of this manuscript.

\section{References}

Al Atik L, Abrahamson N, Bommer JJ, Scherbaum F, Cotton F and Kuehn N (2010). The variability of ground-motion prediction models and its components. Seismological Research Letters, 81(5) 794-801.

Ancheta TD, Darragh RB, Stewart JP, Seyhan E, Silva WJ, Chiou BSJ, Wooddell KE, Graves RW, Kottke AR, Boore DM, and Kishida T (2014). NGA-West2 database, Earthquake Spectra 30(3) 989-1005.

Andrews, IJ (2013). The Carboniferous Bowland Shale gas study: geology and resource estimation. London, UK, British Geological Survey for Department of Energy and Climate Change, 64pp.

Arup (2017). Typology modelling: Analysis results in support of fragility functions - 2017 batch results, Technical report: 229746_031.0_REP2005, November 2017.

Arup (2019). Typology modelling: Analysis results in support of fragility functions - 2018-2019 batch results, June 2019, 90 pp.

Astorga A, Guéguen P and Kashima T (2018). Nonlinear elasticity observed in buildings during a long sequence of earthquakes. Bulletin of the Seismological Society of America, 108(3A) 1185-1198.

Atkinson, GM (2008). Ground-motion prediction equations for eastern North America from a referenced empirical approach: Implications for epistemic uncertainty, Bulletin of the Seismological Society of America 98(3) 1304-1318.

Atkinson GM (2015). Ground-motion prediction equation for small-to-moderate events at short hypocentral distances, with application to induced-seismicity hazards, Bulletin of the Seismological Society of America 105(2A) 981-992. 
Atkinson, GM (2020). The Intensity of Ground Motions from Induced Earthquakes with Implications for Damage Potential, Bulletin of the Seismological Society of America (in press), doi: 10.1785/0120190166.

Baisch S, Koch C and Muntendam-Bos A (2019). Traffic Light Systems: To What Extent Can Induced Seismicity Be Controlled? Seismological Research Letters 90(3) 1145-1154.

Baker JW and Lee C (2018). An improved algorithm for selecting ground motions to match a conditional spectrum, Journal of Earthquake Engineering, 22(4) 708-723.

Bommer JJ, Oates S, Cepeda JM, Lindholm C, Bird J, Torres R, Marroquin G, Rivas J (2006). Control of hazard due to seismicity induced by a hot fractured rock geothermal project, Engineering Geology 83(4) 287-306.

Bommer JJ, Crowley H, Pinho R (2015). A risk-mitigation approach to the management of induced seismicity, Journal of Seismology 19(2) 623-646.

Bommer JJ, Dost B, Edwards B, Stafford PJ, van Elk J, Doornhof D and Ntinalexis M (2016). Developing an application-specific ground-motion model for induced seismicity, Bulletin of the Seismological Society of America, 106(1) 158-173.

Boore DM, Stewart JP, Seyhan E, Atkinson GM (2014). NGA-West2 equations for predicting PGA, PGV, and 5\% damped PSA for shallow crustal earthquakes, Earthquake Spectra 30(3) 1057-1085.

Borzi B, Crowley H, Pinho R (2008). Simplified pushover-based earthquake loss assessment (SP-BELA) method for masonry buildings, International Journal of Architectural Heritage, 2(4) 353-376.

Bradley BA, Dhakal RP, MacRae GA, Cubrinovski M (2010). Prediction of spatially distributed seismic demands in specific structures: Ground motion and structural response, Earthquake Engineering and Structural Dynamics, 39 501-520.

Bradley, BA (2010). A generalized conditional intensity measure approach and holistic ground-motion selection, Earthquake Engineering \& Structural Dynamics, 39(12) 1321- 1342.

British Standards Institute (1993). Evaluation and measurement for vibration in buildings, Part 2: Guide to damage levels from groundborne vibration, BS 7385-2:1993.

Caprio M, Tarigan B, Worden CB, Wiemer S, Wald DJ (2015). Ground motion to intensity conversion equations (GMICEs): A global relationship and evaluation of regional dependency, Bulletin of the Seismological Society of America 105(3) 1476-1490.

Chase RE, Liel AB, Luco N, Bird BW (2019). Seismic loss and damage in light-frame wood buildings from sequences of induced earthquakes, Earthquake Engineering and Structural Dynamics, https://doi.org/10.1002/eqe.3189. 
Clarke H, Eisner L, Styles P, Turner P (2014). Felt seismicity associated with shale gas hydraulic fracturing: The first documented example in Europe, Geophysical Research Letters 41(23) 8308-8314.

Clarke H, Verdon JP, Kettlety T, Baird AF, Kendall JM (2019). Real-Time Imaging, Forecasting, and Management of Human-Induced Seismicity at Preston New Road, Lancashire, England, Seismological Research Letters 90(5) 1902-1915.

Cremen G, Werner MJ, Baptie B (2020). A new procedure for evaluating ground motion models, with application to hydraulic-fracture-induced seismicity in the UK, Bulletin of the Seismological Society of America (in press), doi: 10.1785/0120190238.

Cremen G, Werner MJ (2020). A novel approach to assessing nuisance risk from seismicity induced by UK shale gas development, with implications for future policy design. Natural Hazards and Earth System Sciences, https://doi.org/10.5194/nhess-2020-95.

Crowley H, Polidoro B, Pinho R, van Elk J (2017). Framework for developing fragility and consequence models for local personal risk, Earthquake Spectra 33(4) 1325-1345.

Crowley H, Pinho R, Cavalieri F (2019a). Report on the v6 fragility and consequence models for the Groningen Field, NAM Platform, March 2019.

Crowley H, Pinho R, van Elk J, Uilenreef J (2019b). Probabilistic damage assessment of buildings due to induced seismicity, Bulletin of Earthquake Engineering 17(8) 4495-4516.

Cuadrilla Resources (2019a). Preston New Road-1z HFP report, Technical Report PNR1z-HFP-Report001, 25 pp.

Cuadrilla Resources (2019b). Hydraulic fracture plan PNR 2, Technical Report CORP-HSE-RPT-003, 24 pp.

Deichmann N, Giardini D (2009). Earthquakes induced by the stimulation of an enhanced geothermal system below Basel (Switzerland), Seismological Research Letters 80(5) 784-798.

Deichmann N (2017). Theoretical basis for the observed break in $\mathrm{M}_{\mathrm{L}} / \mathrm{M}_{\mathrm{w}}$ scaling between small and large earthquakes, Bulletin of the Seismological Society of America 107(2) 505-520.

Dost B, Edwards B, Bommer JJ (2018). The relationship between $\mathbf{M}$ and $\mathrm{M}_{\mathrm{L}}$ : a review and application to induced seismicity in the Groningen Gas Field, The Netherlands, Seismological Research Letters 89(3) 1062-1074.

Dost B, Edwards B, Bommer JJ (2019). Erratum: The relationship between $\mathbf{M}$ and $\mathrm{M}_{\mathrm{L}}$ : a review and application to induced seismicity in the Groningen Gas Field, The Netherlands, Seismological Research Letters 90(4) 1660-1662. 
Douglas J, Boore DM (2011). High-frequency filtering of strong-motion records, Bulletin of Earthquake Engineering 9(2) pp.395-409.

Douglas J, Jousset $\mathrm{P}$ (2011). Modeling the difference in ground-motion magnitude-scaling in small and large earthquakes. Seismological Research Letters, 82(4), pp.504-508.

Douglas J, Edwards B, Convertito V, Sharma N, Tramelli A, Kraaijpoel D, Cabrera BM, Maercklin N, Troise $C$ (2013). Predicting ground motion from induced earthquakes in geothermal areas, Bulletin of the Seismological Society of America 103(3) 1875-1897.

Edwards B, Douglas J (2013). Selecting ground-motion models developed for induced seismicity in geothermal areas, Geophysical Journal International 195(2) 1314-1322.

Edwards B, Kraft T, Cauzzi C, Kästli P, Wiemer S (2015). Seismic monitoring and analysis of deep geothermal projects in St Gallen and Basel, Switzerland, Geophysical Journal International 201(2) 1022-1039.

Edwards B, Crowley H, Pinho R (2019). Final Report on: "WP2 - Impacts of seismicity: transmission to people, property and well integrity", Technical Report for the Oil and Gas Authority (OGA), 119pp.

Fellgett MW, Kingdon A, Williams JDO, Gent CMA (2017). State of stress across UK Regions, BGS Open Report OR/17/048, $64 \mathrm{pp}$.

FEMA (2004). HAZUS-MH Technical Manual, Federal Emergency Management Agency, Washington D.C.

Foti S, Hollender S, Garofalo F, Albarello D, Asten M, Bard P-Y, Comina C, Cornou C, Cox B, Di Giulio G, Forbriger T, Hayashi K, Lunedei E, Martin A, Mercerat D, Ohrnberger M, Poggi V, Renalier F, Sicilia D, Socco LV (2017). Guidelines for the good practice of surface wave analysis: a product of the InterPACIFIC project, Bulletin of Earthquake Engineering 16(6) 2367-2420.

Graziotti F, Tomassetti U, Penna A, Magenes M (2019). Tests on URM clay and calcium-silicate masonry structures: identification of damage states, Eucentre Foundation, Pavia, Italy, May 2019.

Green CA, Styles P, Baptie BJ (2012). Preese Hall shale gas fracturing review and recommendations for induced seismic mitigation, Department of Energy and Climate Change, London, 26 pp.

Green RA, Bommer JJ (2019) What is the Smallest Earthquake Magnitude that Needs to be Considered in Assessing Liquefaction Hazard? Earthquake Spectra 35(3) 1441-1464.

Grünthal G, Wahlström R, Stromeyer D (2009). The unified catalogue of earthquakes in central, northern, and northwestern Europe (CENEC) - updated and expanded to the last millennium, Journal of Seismology 13(4) 517-541. 
Hassani B and Atkinson GM (2016). Applicability of the site fundamental frequency as a Vs30 proxy for central and eastern North America, Bulletin of the Seismological Society of America, 106(2) 653-664.

Jayaram N, Baker JW (2009). Correlation model for spatially distributed ground-motion intensities, Earthquake Engineering and Structural Dynamics 38(15) 1687-1708.

Kwiatek G, Saarno T, Ader T, Bluemle F, Bohnhoff M, Chendorain M, Dresen G, Heikkinen P, Kukkonen I, Leary P, Leonhardt $M$ (2019). Controlling fluid-induced seismicity during a 6.1-km-deep geothermal stimulation in Finland, Science Advances 5(5) eaav7224.

Lesueur C, Cara M, Scotti O, Schlupp A and Sira C (2013). Linking ground motion measurements and macroseismic observations in France: a case study based on accelerometric and macroseismic databases. Journal of seismology, 17(2), pp.313-333.

Luckett R, Ottemöller L, Butcher A, Baptie B (2018). Extending local magnitude $M_{L}$ to short distances, Geophysical Journal International 216(2) 1145-1156.

Mancini S, Segou M, Werner MJ, Baptie BJ (2019). Statistical Modelling of the Preston New Road Seismicity: Towards Probabilistic Forecasting Tools. British Geological Survey Commissioned Report, CR/19/068. 41pp.

Miller RD, Park CB, Xia J (1999). Multichannel analysis of surface waves, Geophysics 64: 800-808.

Mosayk (2017). Nonlinear dynamic analysis of index buildings for v5 fragility and consequence models, October 2017.

Ntinalexis, M, Bommer, JJ, Ruigrok, E, Edwards, B, Pinho, R, Dost, B, Correia, AA, Uilenreef, J, Stafford, PJ, van Elk, J, (2019). Ground-motion networks in the Groningen field: usability and consistency of surface recordings, Journal of Seismology, 23(6) 1233-1253.

Silva V, Crowley H, Pagani M, Monelli D, Pinho R (2014). Development of the OpenQuake engine, the Global Earthquake Model's open-source software for seismic risk assessment, Natural Hazards 72(3) 1409-1427.

Taig AR, Pickup FE (2016). Risk Assessment of Falling Hazards in Earthquakes in the Groningen region, Arup Report 229746_032.0_REP1008.

Taig T (2018). Groningen Region Falling Hazard Risk Assessments: An update, October 2018.

van Elk J, Bourne SJ, Oates S, Bommer JJ, Pinho R, Crowley H (2019). A probabilistic model to evaluate options for mitigating induced seismic risk, Earthquake Spectra 35(2) 537-564.

Wald DJ, Quitoriano V, Heaton TH and Kanamori H (1999). Relationships between peak ground acceleration, peak ground velocity, and modified Mercalli intensity in California, Earthquake Spectra, 15(3) 557-564. 
Wathelet M (2008). An improved neighborhood algorithm: parameter conditions and dynamic scaling, Geophysical Research Letters 35 L09301.

Wathelet $M$, Jongmans $D$, Ohrnberger $M$ (2004). Surface wave inversion using a direct search algorithm and its application to ambient vibration measurements, Near Surface Geophysics 2: 211221.

Whitelaw P, Uguna CN, Stevens LA, Meredith W, Snape CE, Vane CH, Moss-Hayes V, Carr AD (2019). Shale gas reserve evaluation by laboratory pyrolysis and gas holding capacity consistent with field data, Nature communications 10(1) 1-10.

Worden CB, Gerstenberger MC, Rhoades DA and Wald DJ (2012). Probabilistic relationships between ground-motion parameters and modified Mercalli intensity in California, Bulletin of the Seismological Society of America, 102(1) 204-221. 


\section{Tables}

Table 1. Direct measurement (MASW based) and indirect ( $V_{R, 40-45}$-proxy based) $V_{S 30}$ at sites L001, L003 and L009.

\begin{tabular}{|c|c|c|c|c|c|c|}
\hline $\begin{array}{l}\text { Surface } \\
\text { Deposit }\end{array}$ & $\begin{array}{l}\text { Lithological } \\
\text { Depths }\end{array}$ & Site & $V_{s 30}$ from $V_{R, 40-45}$ & $\begin{array}{l}V_{s 30} \text { from } \\
V_{s}(z) \\
\text { (median) }\end{array}$ & $\begin{array}{l}V_{s 30} \text { from } \\
V_{s}(z)\left(16^{\text {th }}-\right. \\
\text { percentile })\end{array}$ & $\begin{array}{l}V_{s 30} \text { from } \\
V_{s}(z)\left(84^{\text {th }}-\right. \\
\text { percentile })\end{array}$ \\
\hline Till & $\begin{array}{l}\text { Yes } \\
\text { No }\end{array}$ & L001 & 269.0 & $\begin{array}{l}257.1 \\
249.7\end{array}$ & $\begin{array}{l}251.7 \\
247.6\end{array}$ & $\begin{array}{l}264.4 \\
252.8\end{array}$ \\
\hline $\begin{array}{l}\text { Alluvium } \\
\text { /Peat }\end{array}$ & $\begin{array}{l}\text { Yes } \\
\text { No }\end{array}$ & L003 & 244.3 & $\begin{array}{l}240.0 \\
234.0\end{array}$ & $\begin{array}{l}237.3 \\
233.3\end{array}$ & $\begin{array}{l}244.3 \\
235.7\end{array}$ \\
\hline Sand & Yes & L009 & 213.3 & $\begin{array}{l}205.3 \\
195.5\end{array}$ & $\begin{array}{l}203.3 \\
194.1\end{array}$ & $\begin{array}{l}205.5 \\
196.0\end{array}$ \\
\hline
\end{tabular}


Table 2. HVSR-based fundamental frequencies $\left(\mathrm{f}^{0}\right)$. Upper and lower estimates are indicated along with alternative $\mathrm{V}_{\mathrm{s} 30}$ using combinations of mean/max bedrock depth and $\mathrm{f}^{0}$ and its upper/lower estimate.

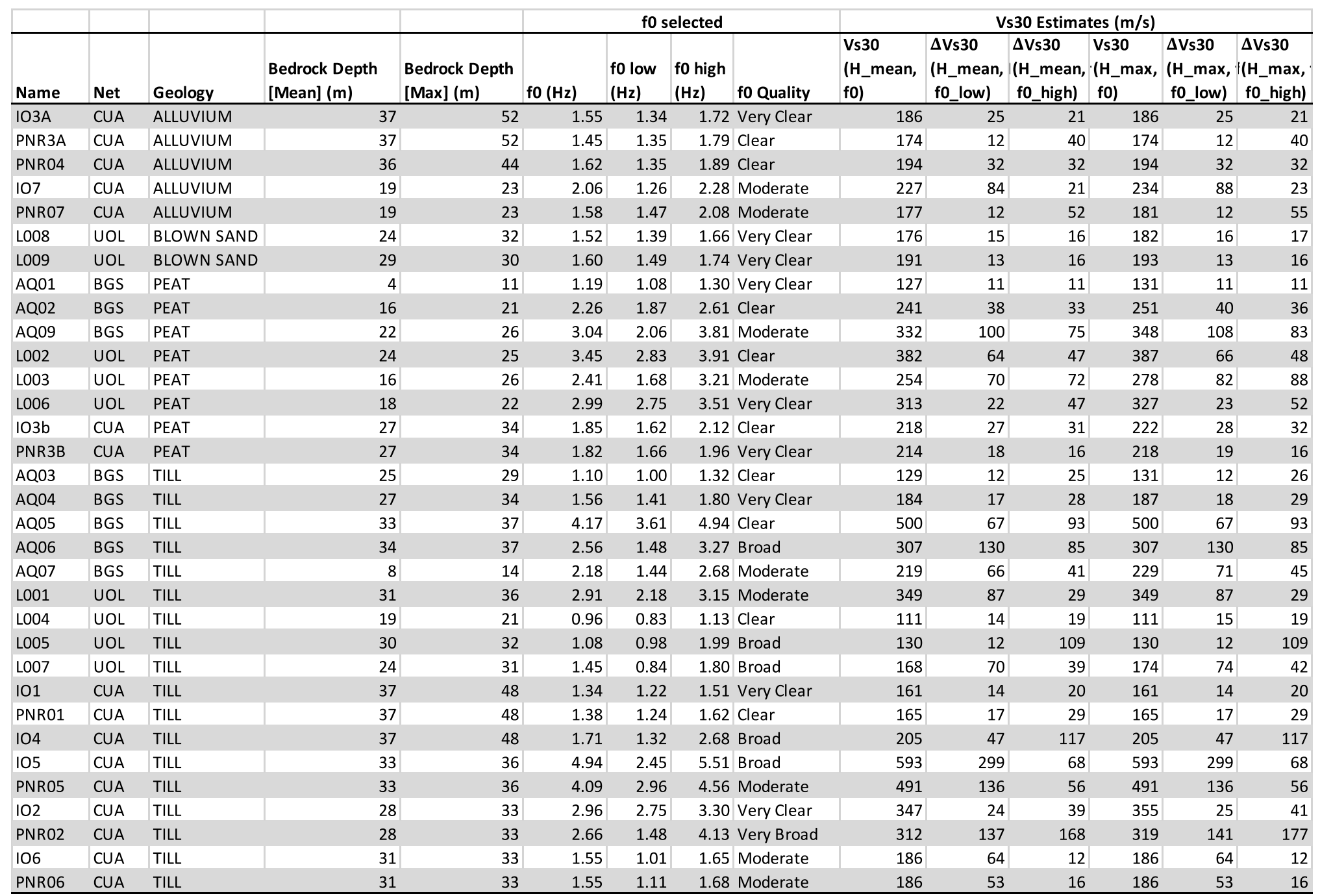


Table 3. Coefficients of the adjusted GMPE for $\mathbf{M}<3$. Coefficients for $\mathbf{M} \geq 3$ should be linearly interpolated from the values here (valid at $\mathbf{M}=3$ ) to the original (Atkinson, 2015) values at $\mathbf{M}=4.5$ (Equation 8, Table 4). Ground motion variability as recommended for implementation is based on the original (Atkinson, 2015) values, using $0.67 \tau$.

\begin{tabular}{rcccccccc}
$\mathbf{F}(\mathbf{H z})$ & $\boldsymbol{T}(\mathbf{s})$ & $\mathbf{d}_{\mathbf{0}}$ & $\mathbf{d}_{\mathbf{1}}$ & $\mathbf{d}_{\mathbf{2}}$ & $\mathbf{d}_{\mathbf{3}}$ & $\boldsymbol{\tau}$ & $\boldsymbol{\phi}$ & $\boldsymbol{\sigma}_{\boldsymbol{T}}$ \\
\hline 2 & 0.50 & -3.7392 & 2.0021 & -0.0998 & -1.7760 & 0.1340 & 0.29 & 0.319 \\
3.33 & 0.30 & -3.6621 & 2.2557 & -0.1634 & -1.4672 & 0.1273 & 0.30 & 0.326 \\
5 & 0.20 & -3.0950 & 2.2584 & -0.1703 & -1.6525 & 0.1407 & 0.30 & 0.331 \\
10 & 0.10 & -1.9083 & 2.1025 & -0.1627 & -2.0590 & 0.1675 & 0.29 & 0.335 \\
20 & 0.05 & -0.8734 & 1.6872 & -0.0978 & -2.5631 & 0.2010 & 0.28 & 0.345 \\
33 & 0.03 & -1.1299 & 1.7556 & -0.1045 & -2.5936 & 0.1809 & 0.28 & 0.333 \\
& PGA & -1.6156 & 1.7605 & -0.1070 & -2.2639 & 0.1608 & 0.28 & 0.323 \\
& PGV & -3.6019 & 1.6791 & -0.0716 & -2.1651 & 0.1273 & 0.27 & 0.299
\end{tabular}

Table 4. Adjustment coefficients and (absolute values of) ground motion variability in the PNR data from Equation 6. Betweenevent $(\tau)$, within-event $(\phi)$, site-to-site $\left(\phi_{S 2 S}\right)$ and total $\left(\sigma_{T}\right)$ variability are determined according to the definitions in Al Atik et al. (2010).

\begin{tabular}{|c|c|c|c|c|c|c|c|c|c|c|c|}
\hline$F(\mathrm{~Hz})$ & $T(s)$ & $\Delta c_{0}$ & $\Delta c_{1}$ & $\Delta c_{2}$ & $\Delta c_{3}$ & $\tau$ & $\phi$ & $\phi_{S 2 S}$ & $\sigma_{T}$ & $\begin{array}{l}\text { No. } \\
\text { Events }\end{array}$ & $\begin{array}{l}\text { No. } \\
\text { Records }\end{array}$ \\
\hline 2 & 0.50 & 0.1338 & -0.0579 & 0.0214 & -0.2320 & 0.0854 & 0.2034 & 0.2049 & 0.2206 & 19 & 144 \\
\hline 3.33 & 0.30 & -0.8681 & 0.4037 & -0.0556 & 0.1408 & 0.0803 & 0.2318 & 0.2207 & 0.2453 & 23 & 199 \\
\hline 5 & 0.20 & -0.8290 & 0.4734 & -0.0642 & 0.0045 & 0.0559 & 0.2366 & 0.2058 & 0.2432 & 23 & 246 \\
\hline 10 & 0.10 & 0.0457 & 0.2725 & -0.0442 & -0.2850 & 0.0359 & 0.2684 & 0.2234 & 0.2708 & 23 & 299 \\
\hline 20 & 0.05 & 1.1446 & -0.1388 & 0.0214 & -0.7321 & 0.0624 & 0.2619 & 0.2079 & 0.2693 & 23 & 301 \\
\hline 33 & 0.03 & 1.1531 & -0.0864 & 0.0144 & -0.8086 & 0.0828 & 0.3789 & 0.2861 & 0.3879 & 23 & 301 \\
\hline & PGA & 0.7604 & -0.0575 & 0.0083 & -0.5119 & 0.0640 & 0.3192 & 0.2569 & 0.3255 & 23 & 301 \\
\hline & PGV & 0.5491 & -0.0829 & 0.0235 & -0.4961 & 0.0585 & 0.3015 & 0.2178 & 0.3071 & 23 & 299 \\
\hline
\end{tabular}

Table 5. Mapping scheme for the proportion of building class for each land class.

\begin{tabular}{|l|l|l|l|l|}
\hline Building Class & Rural & Urban & Industrial & Sports/Leisure \\
\hline Brick masonry detached & 0.9 & 0.6 & - & 0.2 \\
\hline Brick masonry terraced & 0.1 & 0.4 & - & - \\
\hline Mobile home & - & - & - & 0.8 \\
\hline Light steel frame & - & - & 1.0 & - \\
\hline
\end{tabular}


Table 6. Summary of scenario damage. Italic text indicates thresholds for significance occurrence (median of $\geq 30$ buildings) of a given damage state.

\begin{tabular}{|c|c|c|c|c|c|c|c|c|c|c|}
\hline \multirow[b]{2}{*}{$\begin{array}{l}\text { Scenario } \\
\left(\mathrm{M}_{\mathrm{L}}\right)\end{array}$} & \multicolumn{2}{|c|}{ DS1 } & \multicolumn{2}{|c|}{ DS2 } & \multicolumn{2}{|c|}{ DS3 } & \multicolumn{2}{|c|}{ DS4 } & \multicolumn{2}{|c|}{ Chimney failure } \\
\hline & Mean & Median & Mean & Median & Mean & Median & Mean & Median & Mean & Median \\
\hline 2.1 & 1 & 0 & 0 & 0 & 0 & 0 & 0 & 0 & 0 & 0 \\
\hline 2.5 & 7 & 0 & 0 & 0 & 0 & 0 & 0 & 0 & 0 & 0 \\
\hline 2.9 & 75 & 17 & 10 & 0 & 2 & 0 & 0 & 0 & $<1$ & 0 \\
\hline 3 & 162 & 39 & 28 & 1 & 10 & 0 & 2 & 0 & 5 & 0 \\
\hline 3.5 & 992 & 536 & 301 & 50 & 110 & 3 & 49 & 0 & 65 & 6 \\
\hline 4 & 3243 & 2495 & 1449 & 693 & 709 & 163 & 453 & 19 & 436 & 99 \\
\hline 4.5 & 5835 & 5606 & 3257 & 2290 & 1824 & 879 & 1401 & 267 & 1195 & 456 \\
\hline
\end{tabular}




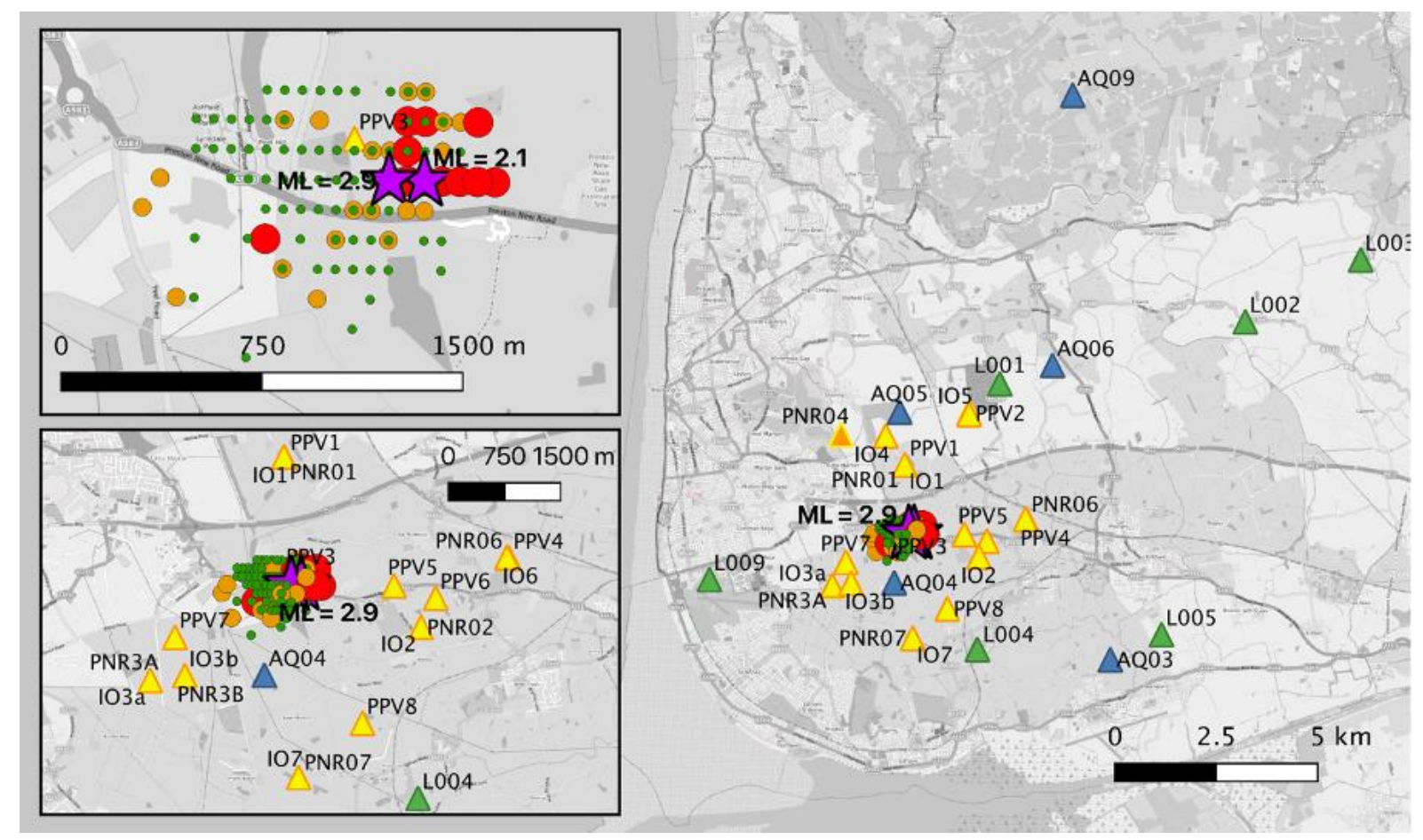

Figure 1. Seismic monitoring stations [triangles, operated by Cuadrilla (sites labelled IO1-7, PNR1-7 and PPV1-7); UoL (labelled L001-9); BGS (labelled AQ01-9)]. Detected seismic events during both the 2018 and 2019 injections are shown (colours or symbol size indicating their TLS category: red, yellow and green, from large to small circles, respectively). The locations of the largest two events (ML 2.1 and 2.9) are indicated by stars. The epicentral region is shown in the inset figures (top: $\mathrm{R}_{\text {epi }}<\sim 0.5 \mathrm{~km}$; bottom: $\mathrm{R}_{\text {epi }}<\sim 5 \mathrm{~km}$ ).
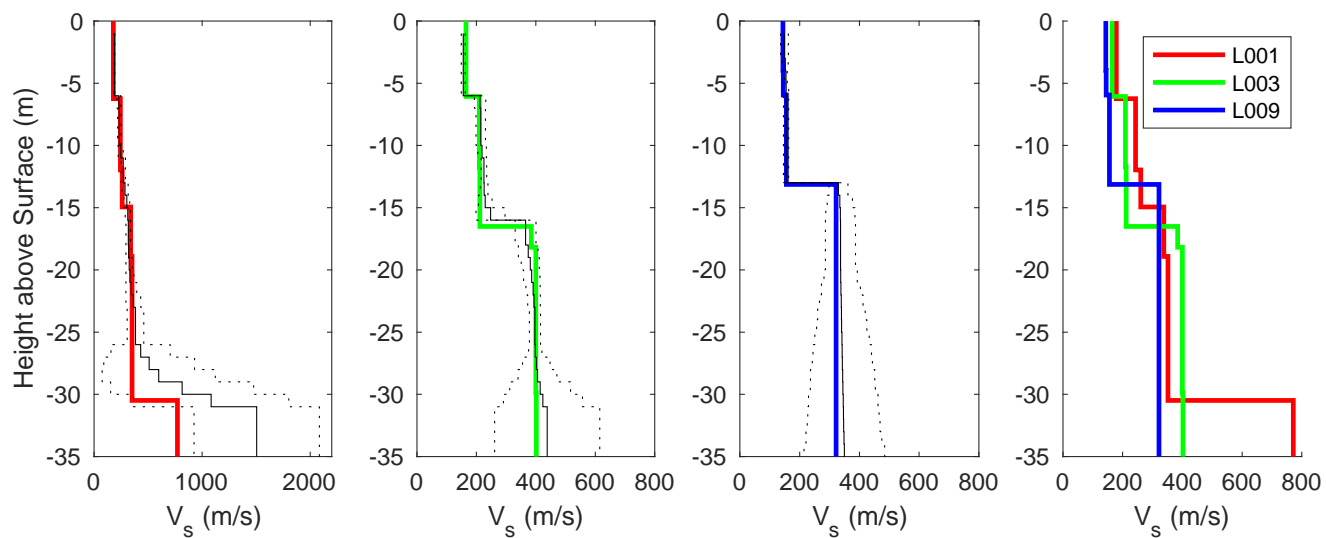

Figure 2. Ground profiles $\left(\mathrm{V}_{\mathrm{s}}\right)$ for site L001, L003 and L009, from left to right, respectively, with all three compared in the right panel. Bold lines indicate the 'best-fit' models, while the black solid and dotted lines indicate the mean and one standard deviation of models within a misfit tolerance that fully encapsulates the observed dispersion curve. 


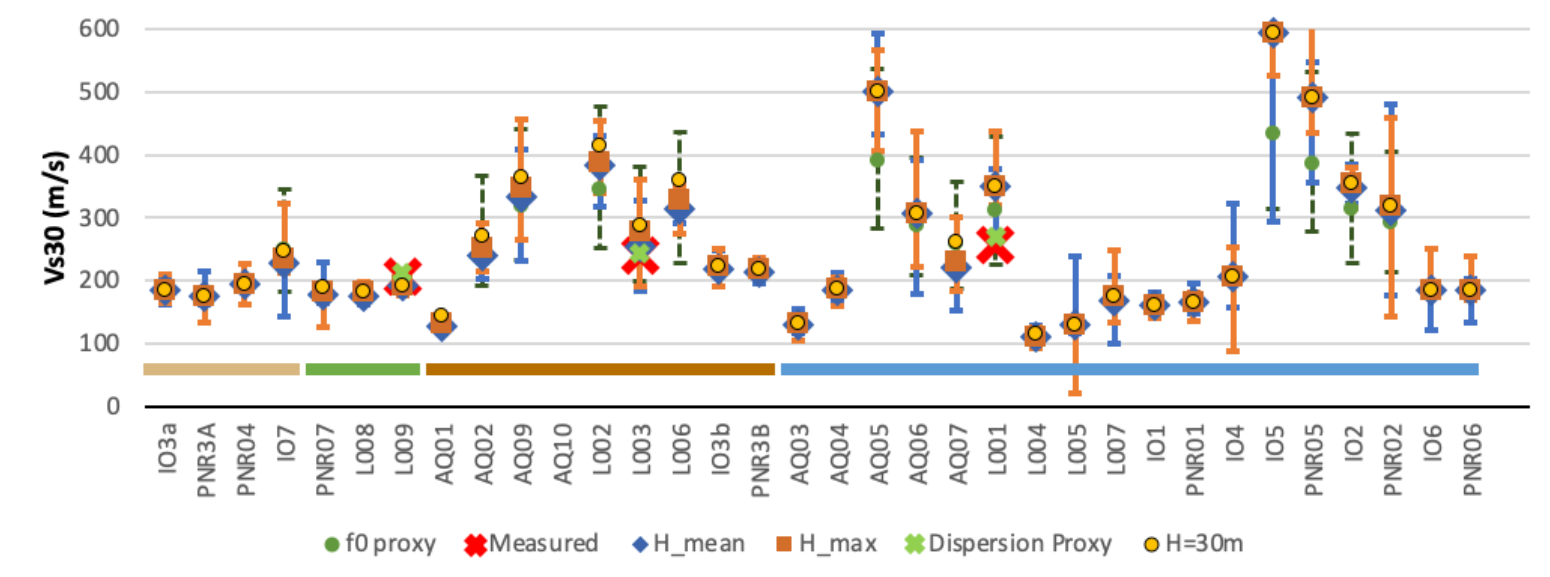

Figure 3. $\mathrm{V}_{\mathrm{s} 30}$ grouped by surface geology. Empirical $\mathrm{V}_{\mathrm{s} 30}$ based on an ' $\mathrm{f}^{0}$ proxy' (Hassani and Atkinson, 2016) are shown, along with their uncertainty (dashed error bars). Lower- and higher-estimates of $\mathrm{f}^{0}$-based $\mathrm{V}_{\mathrm{s} 30}$ (Table 2) define the error bars for each of the assumed bedrock depths ('H_mean', 'H_max' and 'H=30m', as indicated in the legend). The 'measured' (MASW-based) and 'dispersion proxy' based $V_{s 30}$ (Table 1) are also shown. Surface geology class in indicated by the horizontal bars, from left to right: alluvium, blown-sand, peat, and till.

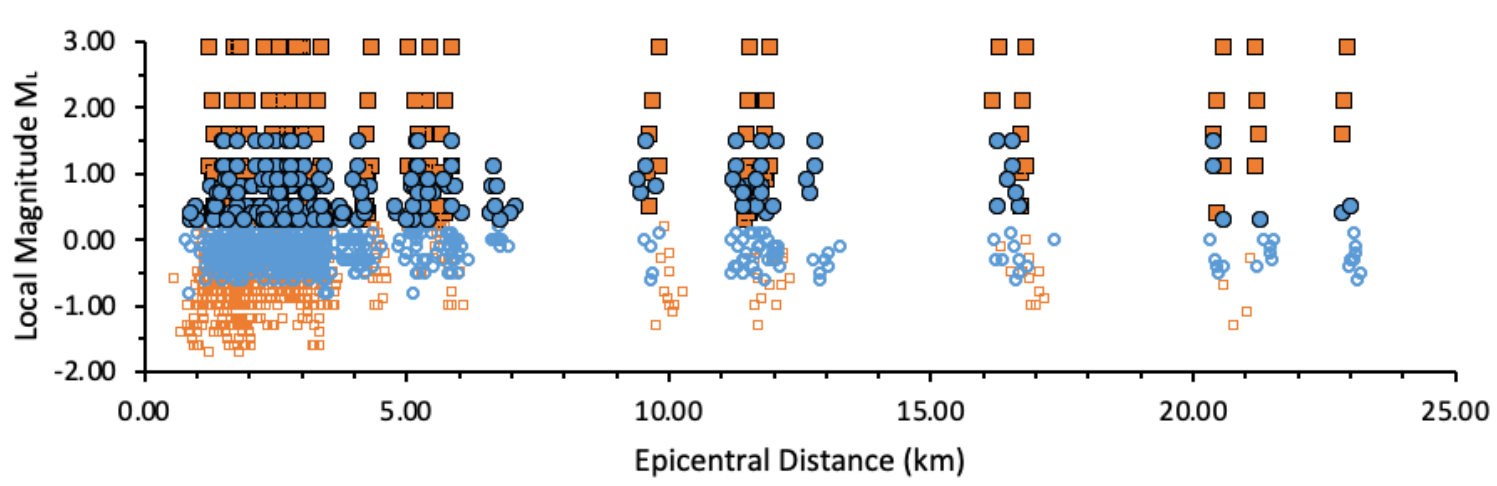

Figure 4. Distance vs. magnitude for the usable data. Circles show the data from 57 events during the 2018 injection, while squares show the 135 events from the 2019 injection phases. Filled symbols $\left(\mathrm{M}_{\mathrm{L}}>0.25\right)$ indicate records used in the GMPE calibration. 

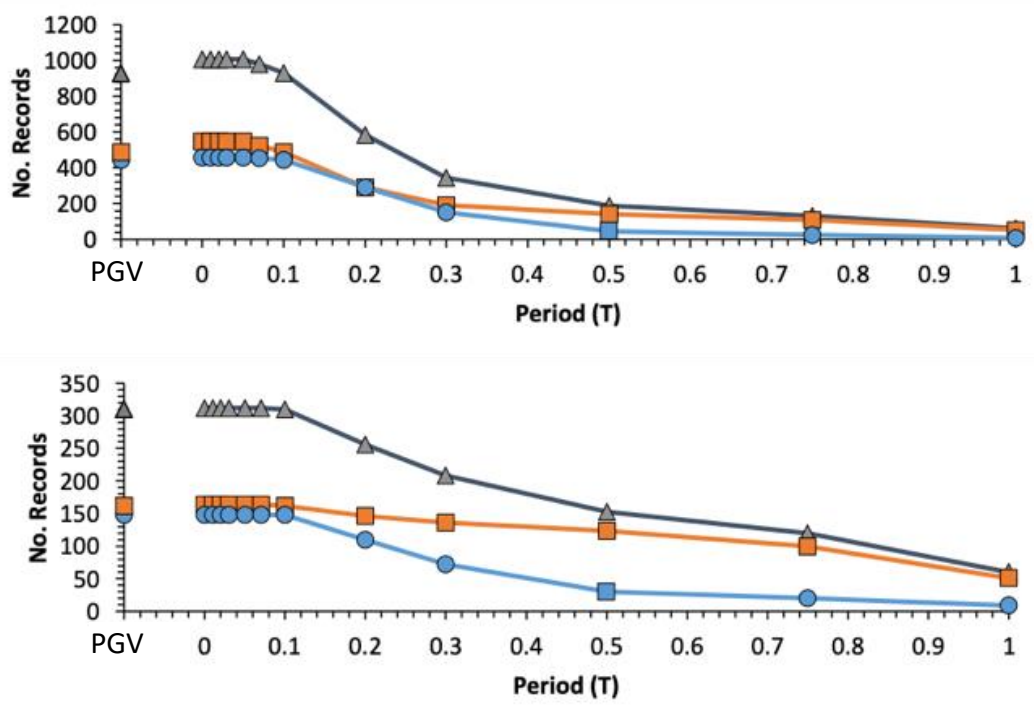

Figure 5. Number of usable records vs. period and PGV. Top: all data, bottom: data with $\mathbf{M}>1$. Circles: data from 57 events during the 2018 injection; squares: data from 135 from the 2019 injection; triangles: combined dataset.

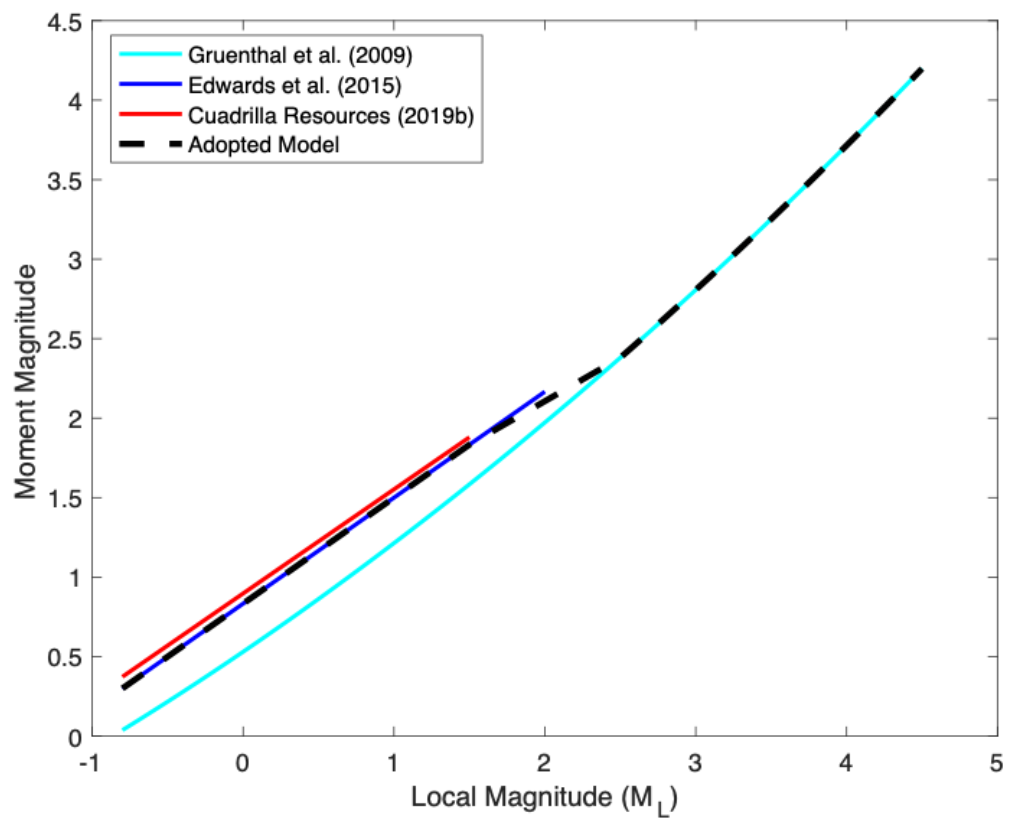

Figure 6. Local to moment magnitude conversions. 


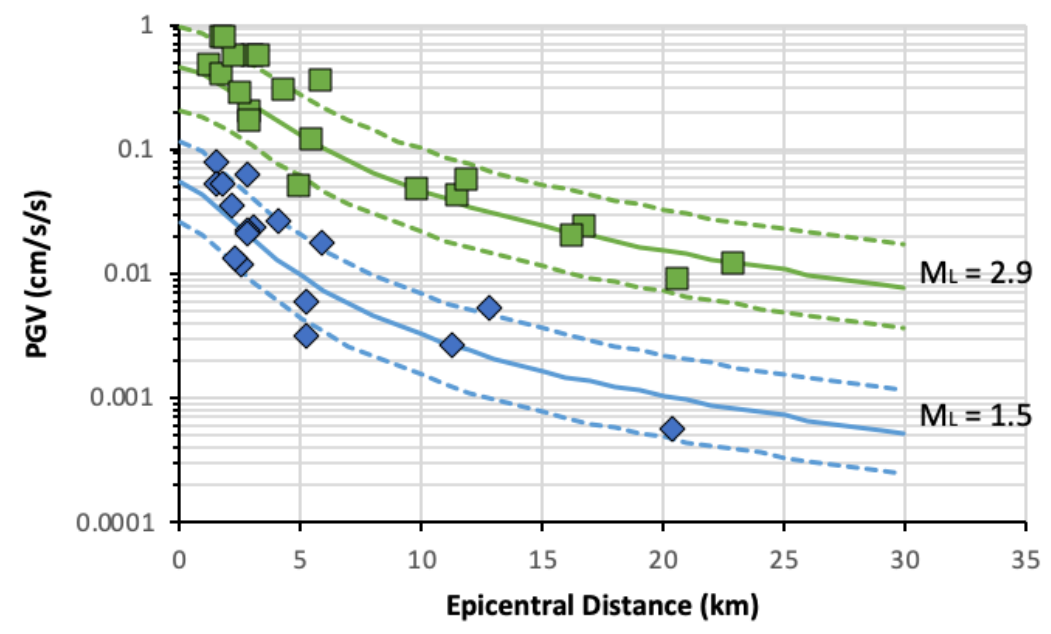

Figure 7. Geometric mean horizontal PGV (largest 2018 event, $\mathrm{M}_{\mathrm{L}}=1.5$; largest 2019 event, $\mathrm{M}_{\mathrm{L}}=2.9$ ) compared to the model of Atkinson (2015) (solid line: median; dashed line: plus/minus one sigma) using $V_{S 30}=240 \mathrm{~m} / \mathrm{s}$ (a representative fieldaverage) and the $\mathrm{M}_{\mathrm{L}}$ to $\mathrm{M}$ conversion adopted for this study (Equations 3, 5).
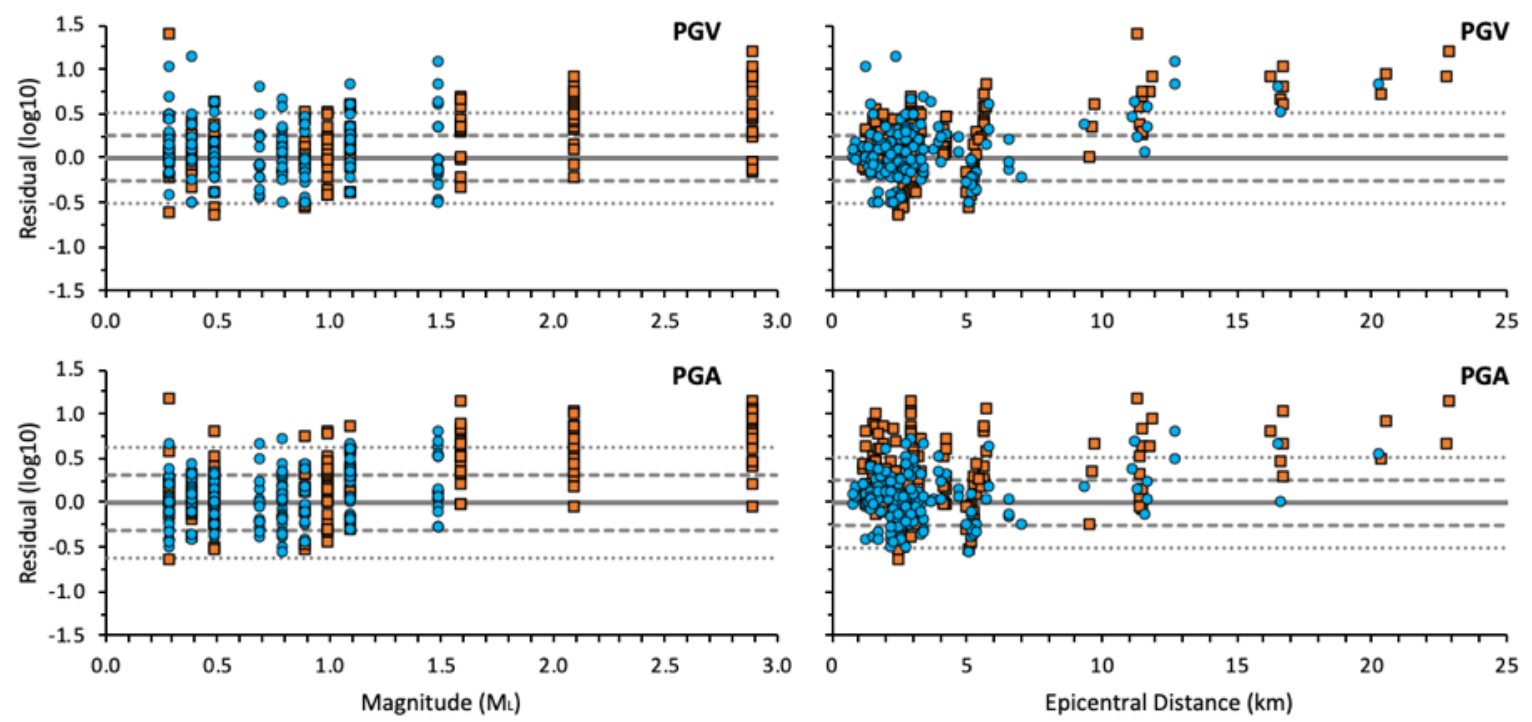

Figure 8. Residuals [log-10 difference: observation - Cremen et al. (2020)] for PGV and PGA versus magnitude and distance. Diamonds represent the data from 57 events during the 2018 injection, while squares represent the data from 135 events during the 2019 injection. The dashed and dotted lines show the one and two sigma levels of the Cremen et al. (2020) model. 

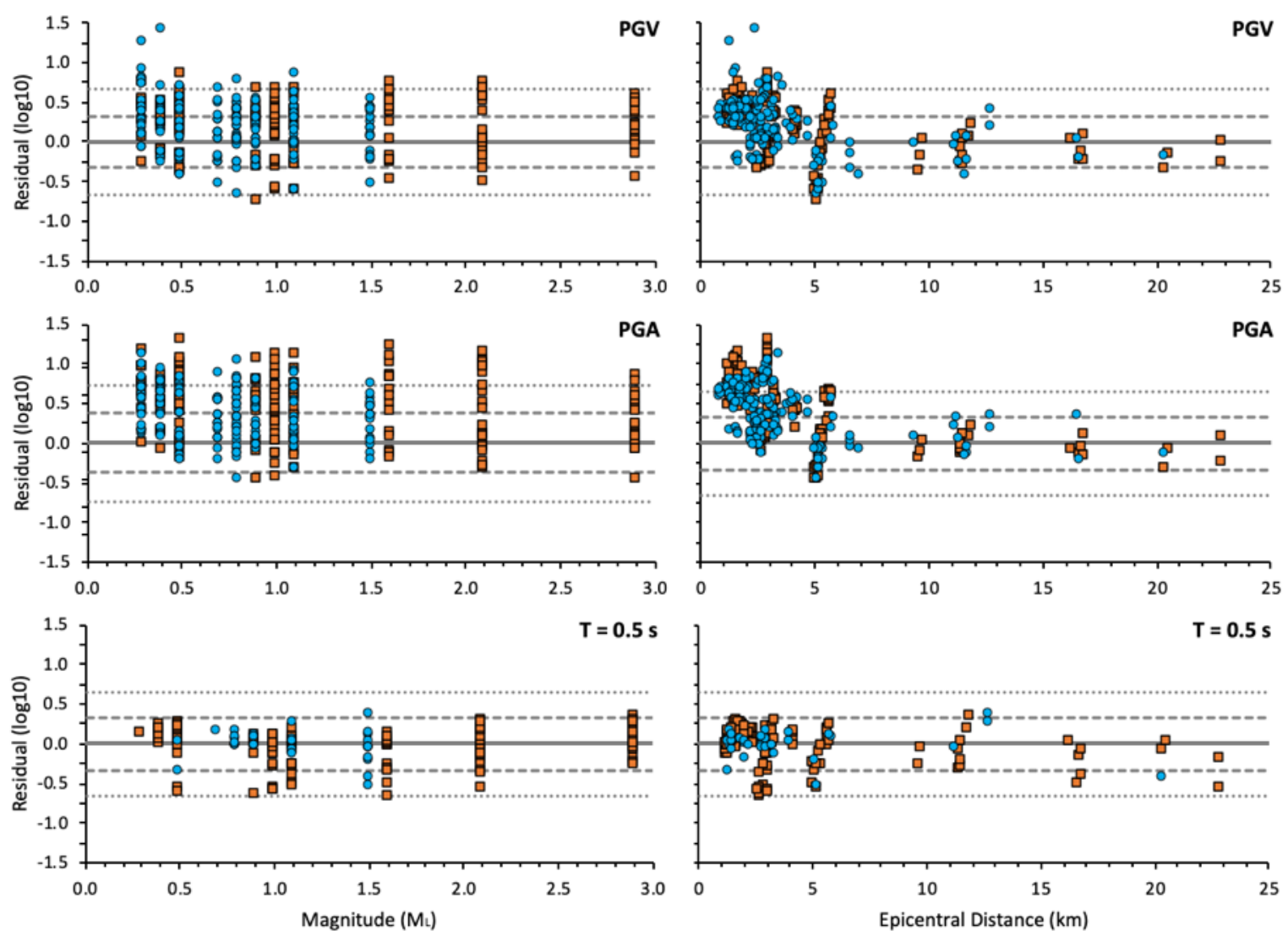

Figure 9. Residuals [log-10 difference: observation - Atkinson (2015)] for PGV, PGA and 0.5 s PSA versus magnitude and distance. Diamonds represent the data from 57 events during the 2018 injection, while squares represent the data from 135 events from the 2019 injection. The dashed and dotted lines show the one and two sigma levels of the Atkinson (2015) model.
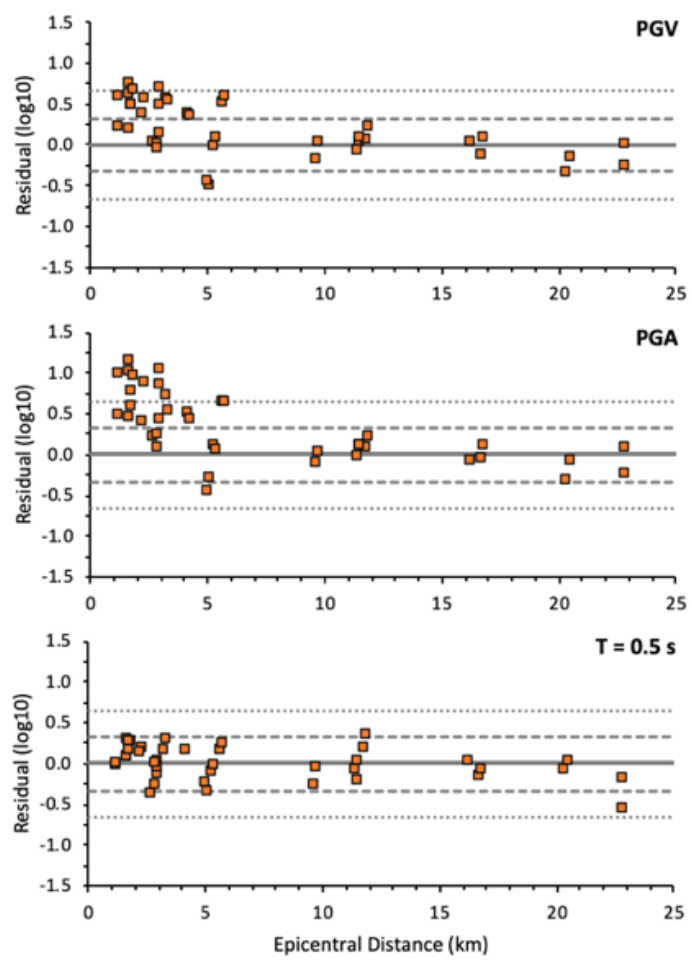

Figure 10. As Figure 7, but showing only residuals for the largest $\left(\mathrm{M}_{\mathrm{L}} 2.1\right.$ and 2.9) events. 

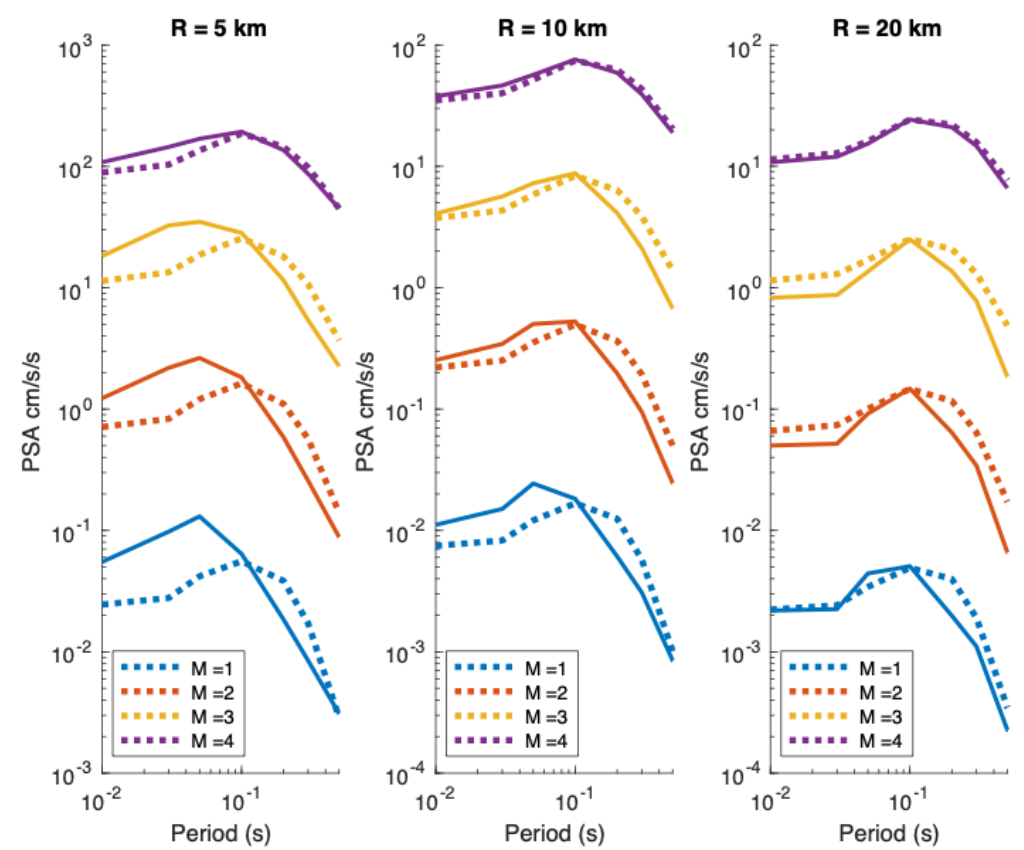

Figure 11. Predicted PSA for M 1 (bottom) to 4 (top) versus period for the original (dotted lines) and adjusted (solid lines) GMPEs. Note, predicted PSA is linearly interpolated in the log-log space between the published periods.
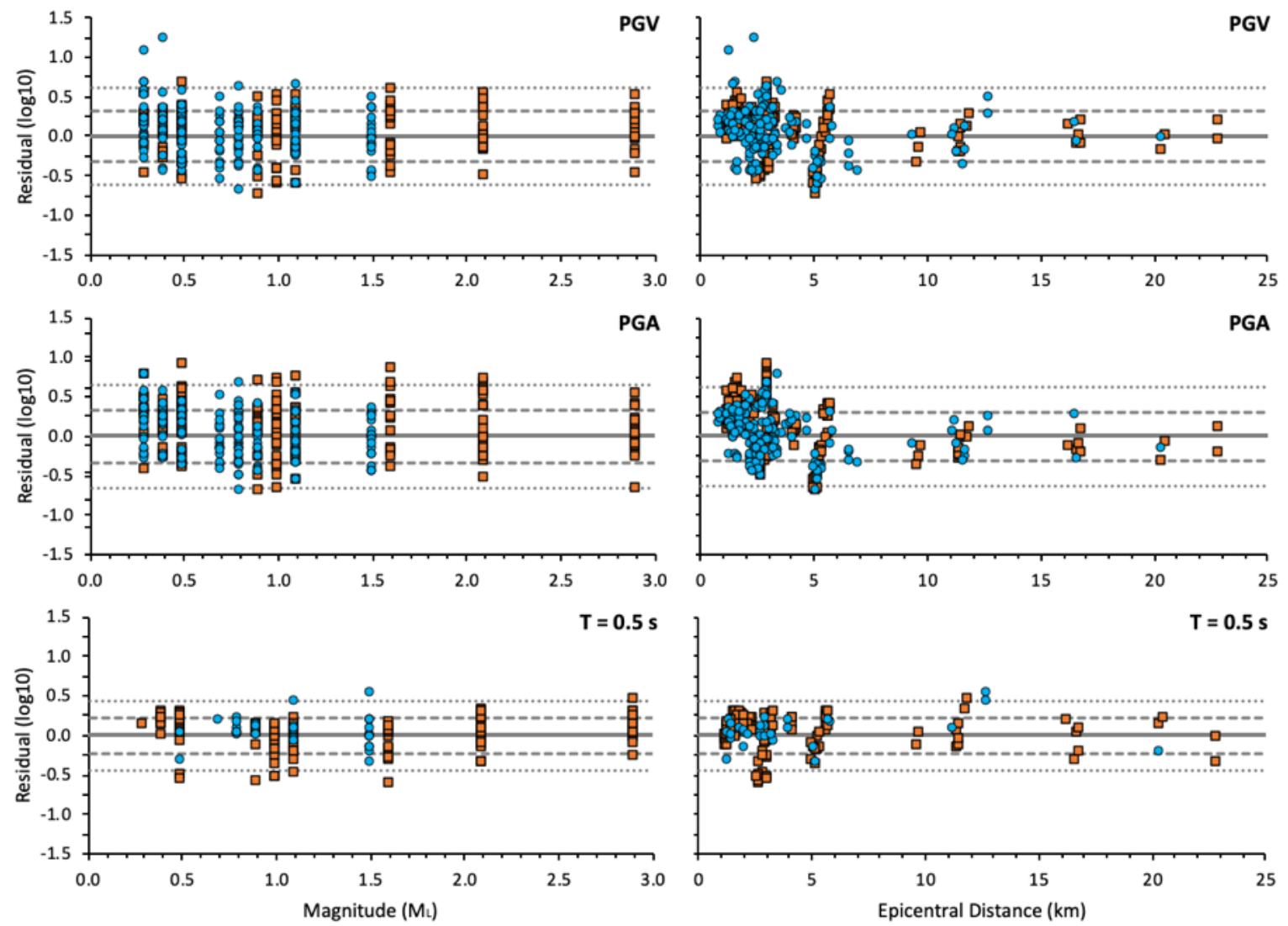

Figure 12. Residuals [log-10 difference: observation - calibrated GMPE] for PGV, PGA and $0.5 \mathrm{~s}$ PSA versus magnitude and distance. Diamonds represent the data from 57 events during the 2018 injection, while squares represent the data from 135 events from the 2019 injection. The dashed and dotted lines show the one and two sigma levels of the calibrated model. 


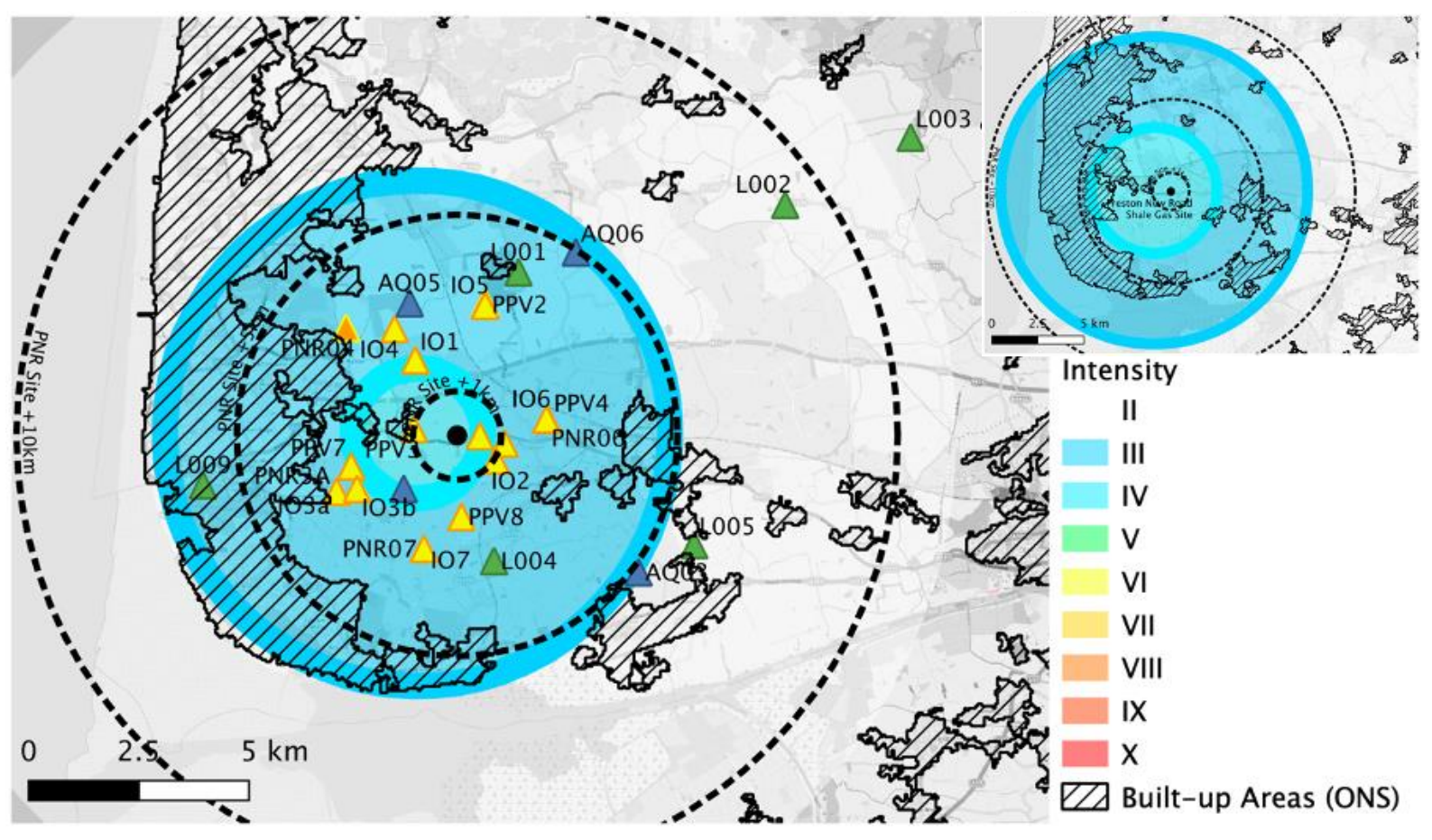

Figure 13. Macroseismic intensity for the $\mathrm{M}_{\mathrm{L}} 2.9$ event (epicentral intensity IV) using median predictions of geometrical mean PGV (inset: intensity using $84^{\text {th }}$ percentile PGV). Seismic monitoring stations are indicated by triangles. The black dot and dashed circles around it indicate the PNR site itself and 1, 5 and $10 \mathrm{~km}$ distances from it.

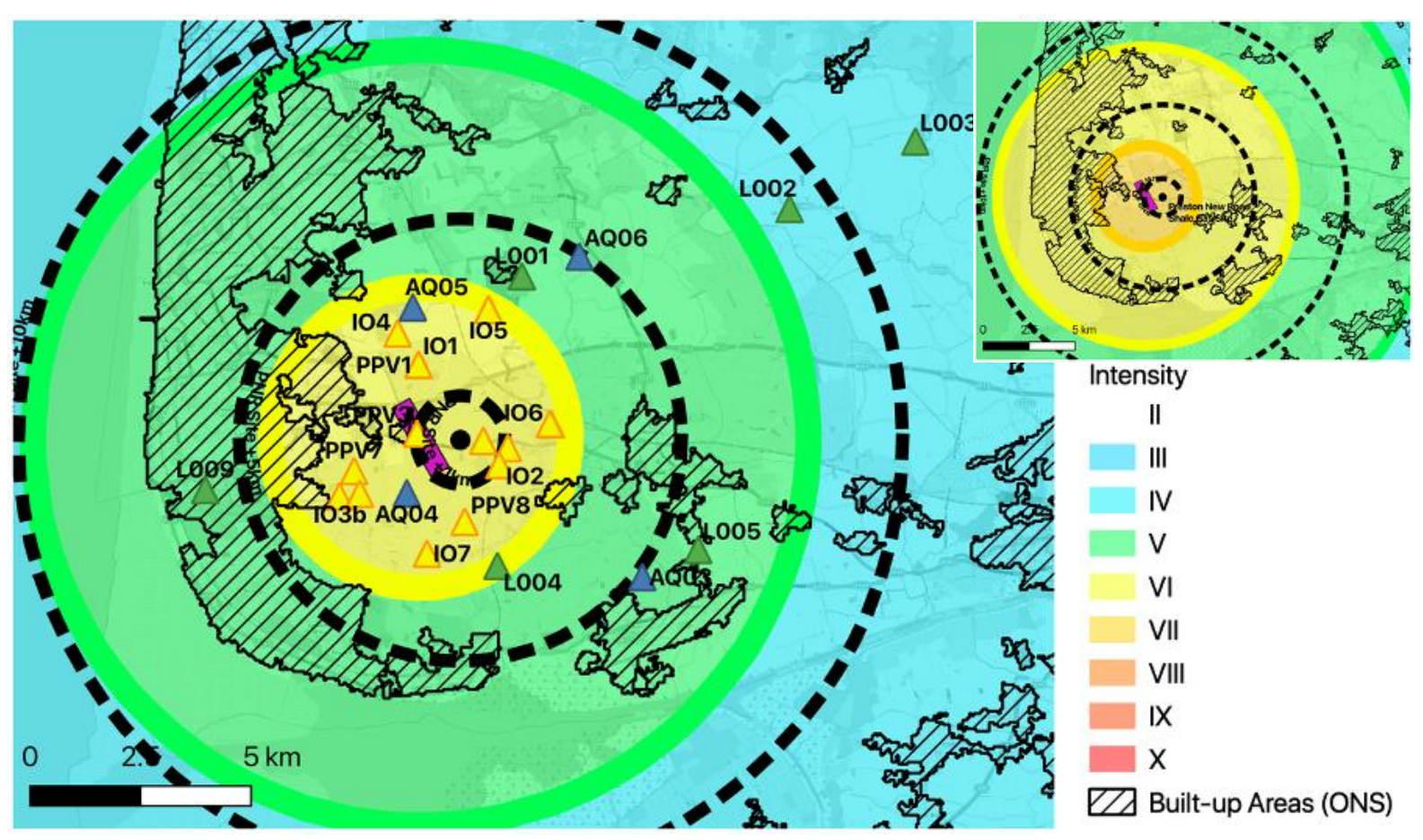

Figure 14. As Fig 13. showing macroseismic intensity for the $\mathrm{M}_{\mathrm{L}} 4.5$ (epicentral intensity VI) event based on median PGV (inset: intensity using $84^{\text {th }}$ percentile PGV). The black dot and dashed circles around it indicate the PNR site itself and 1, 5 and $10 \mathrm{~km}$ distances from it. 


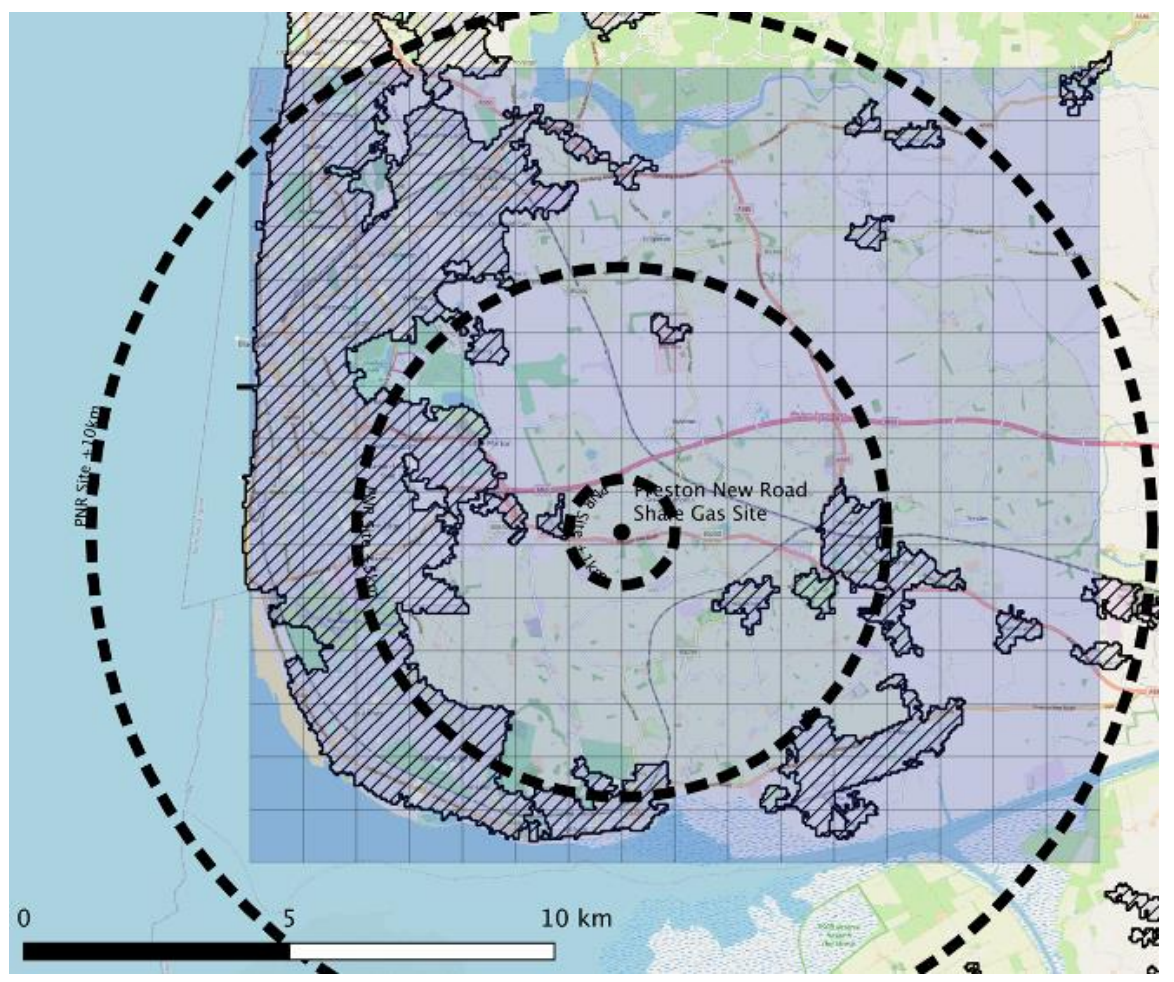

Figure 15. Extent of the exposure model. The risk grid (blue) is 16 x $15 \mathrm{~km}$ at $1 \mathrm{~km}$ intervals. 
(a)

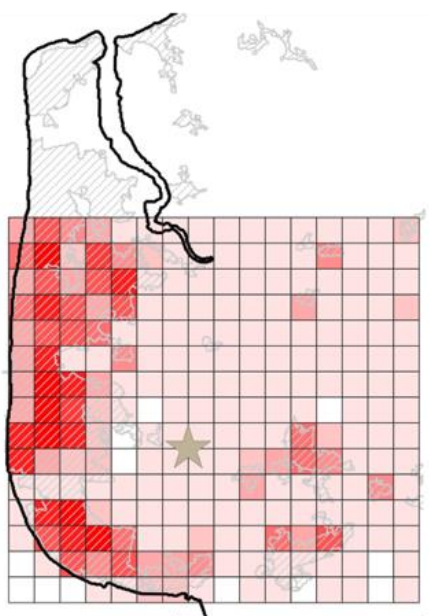

(c)

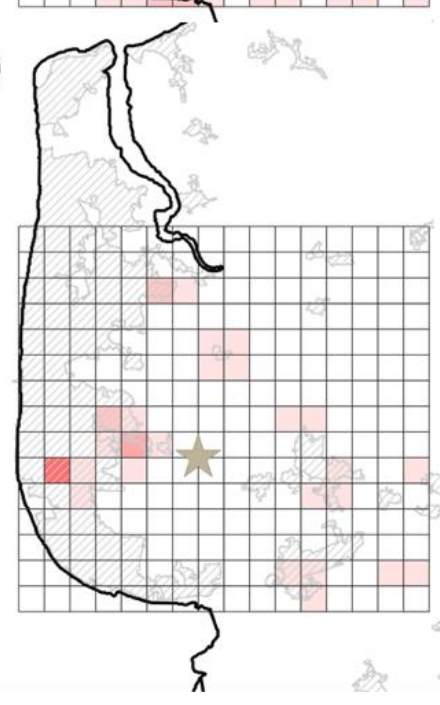

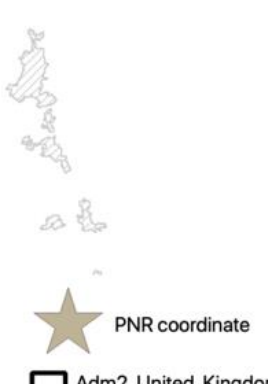

$\square$ Adm2_United_Kingdo BuiltUpAreas

Number of buildings

$\square 0$-0

$\square-146$

$\square$
$146-218$
$\quad 218-291$

$218-291$
$291-364$

$291-364$

$364-437$

437-509

509-582

$582-655$
$655-728$

as

多

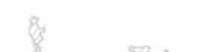

3

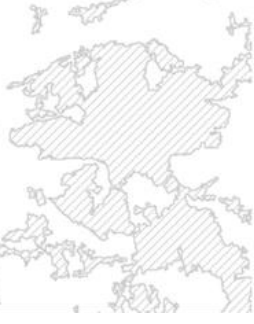

(b)

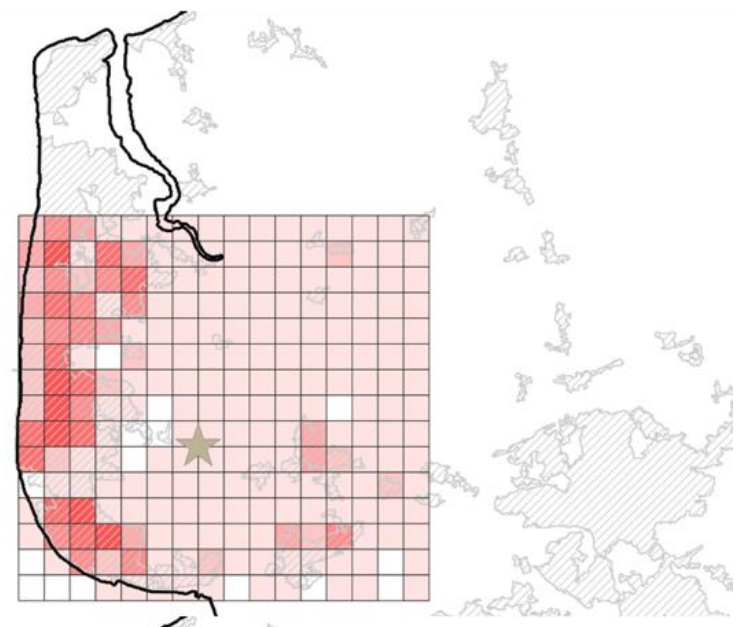

(d)

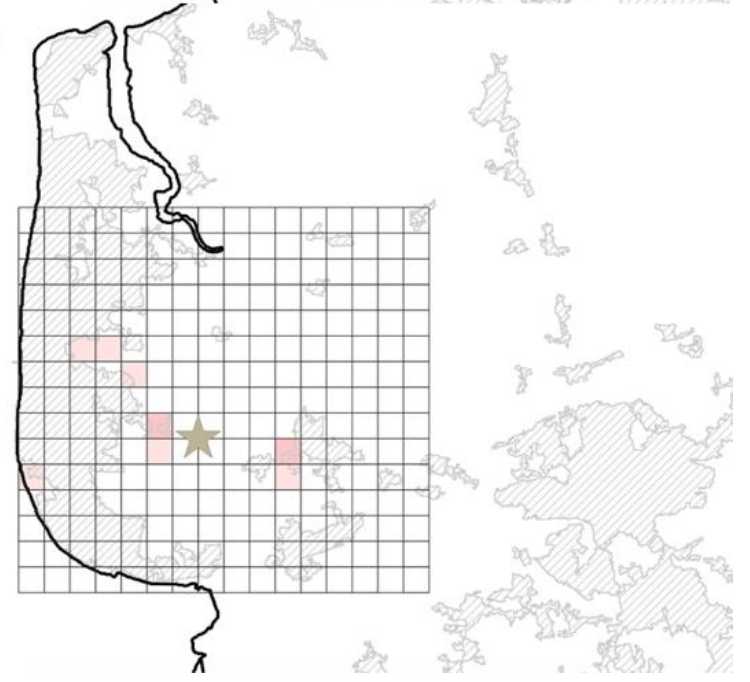

2 Figure 16. Distribution of building classes in the exposure model (a) brick masonry detached, (b) brick masonry terraced, (c) light steel frame, (d) mobile home. 
(a)

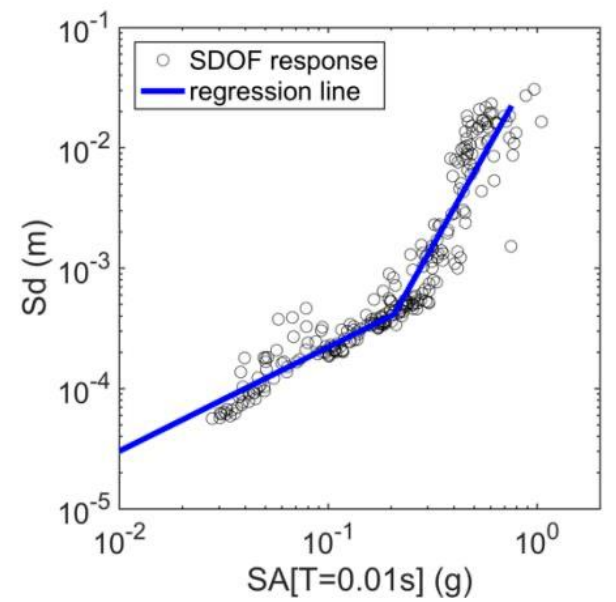

(c)

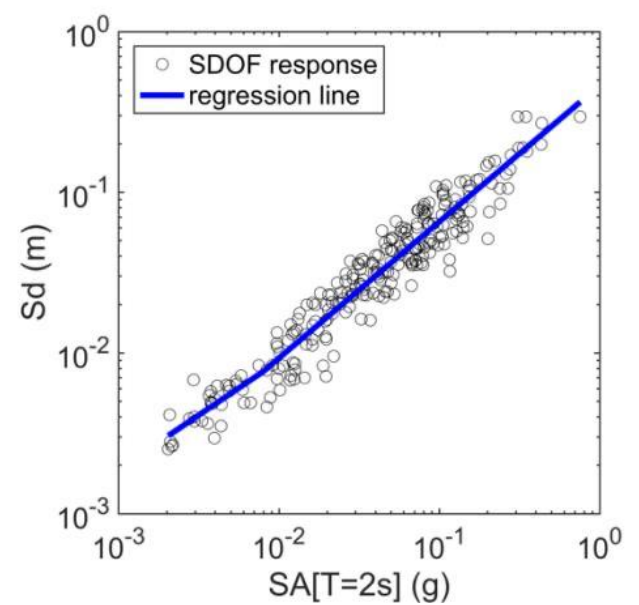

(b)

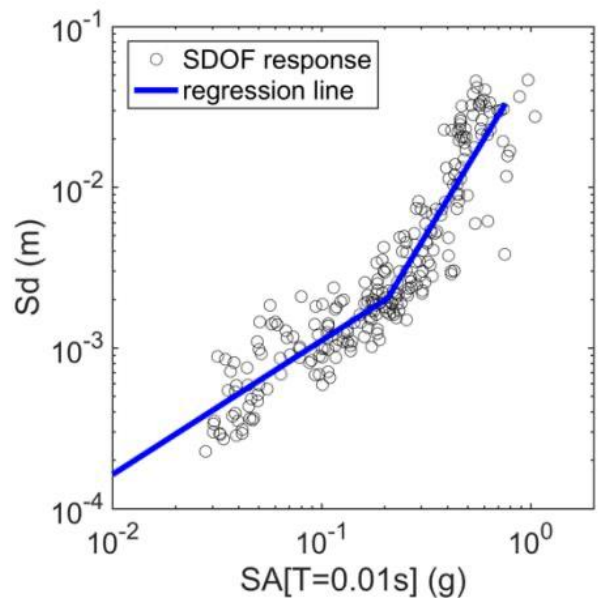

(d)

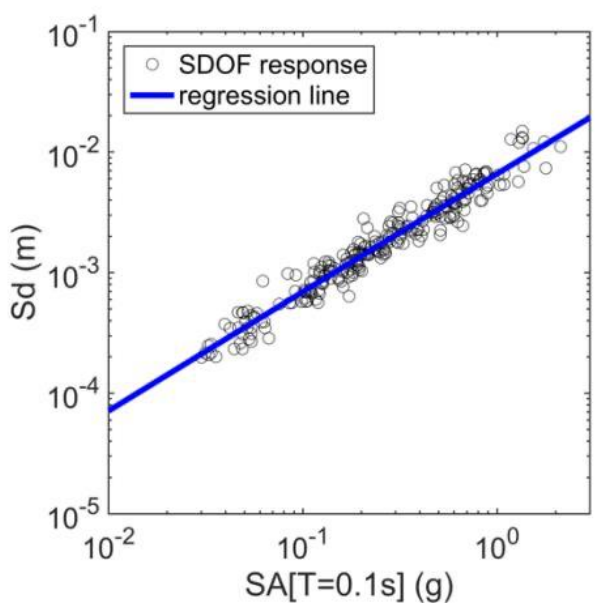

5 Figure 17. Response analyses (input spectral acceleration, SA vs. spectral displacement, SD, response) for SDOF models and 6 corresponding piecewise linear regression: (a) detached, (b) terraced, (c) mobile home and (d) light steel frame. 
(a)

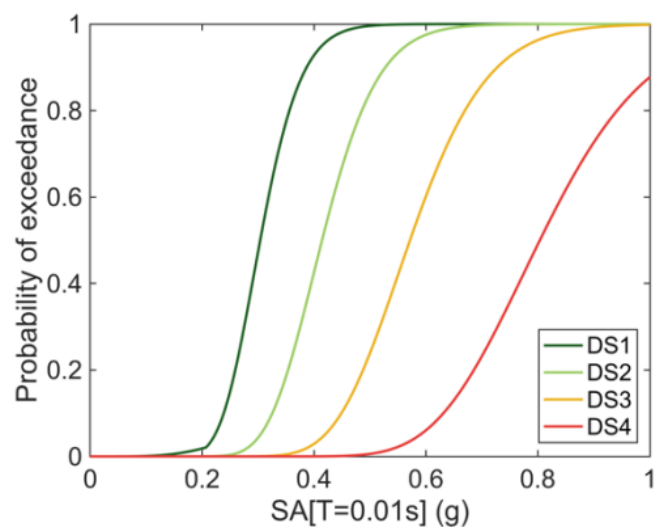

(c)

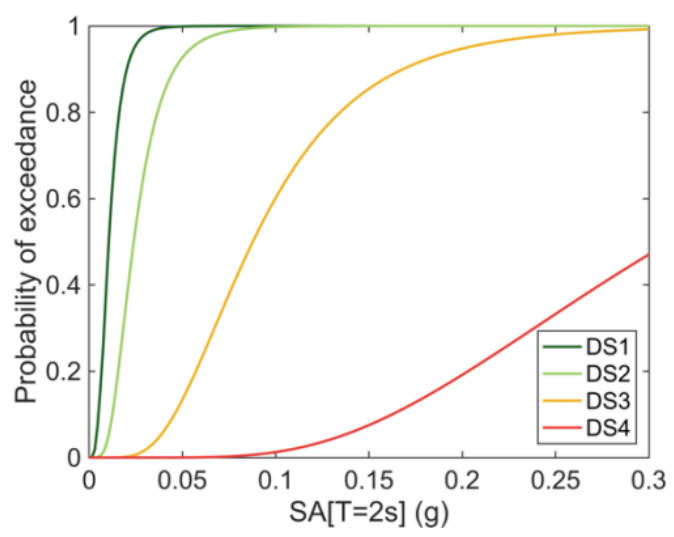

(b)

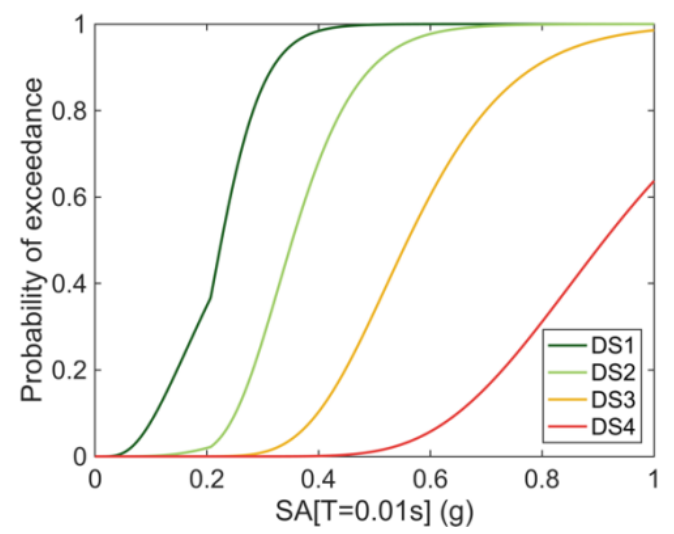

(d)

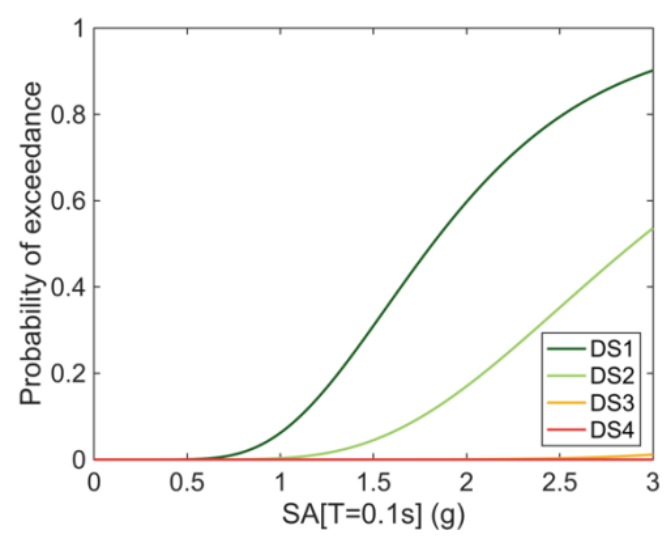

10 Figure 18. Building fragility functions (probability of exceeding a given damage state) for (a) detached, (b) terraced, (c) mobile

11 home and (d) light steel frame buildings for various damage states. The discontinuity evident in the DS1 curve for terraced housing is an artefact of the bilinear regression shown in Figure 17. 


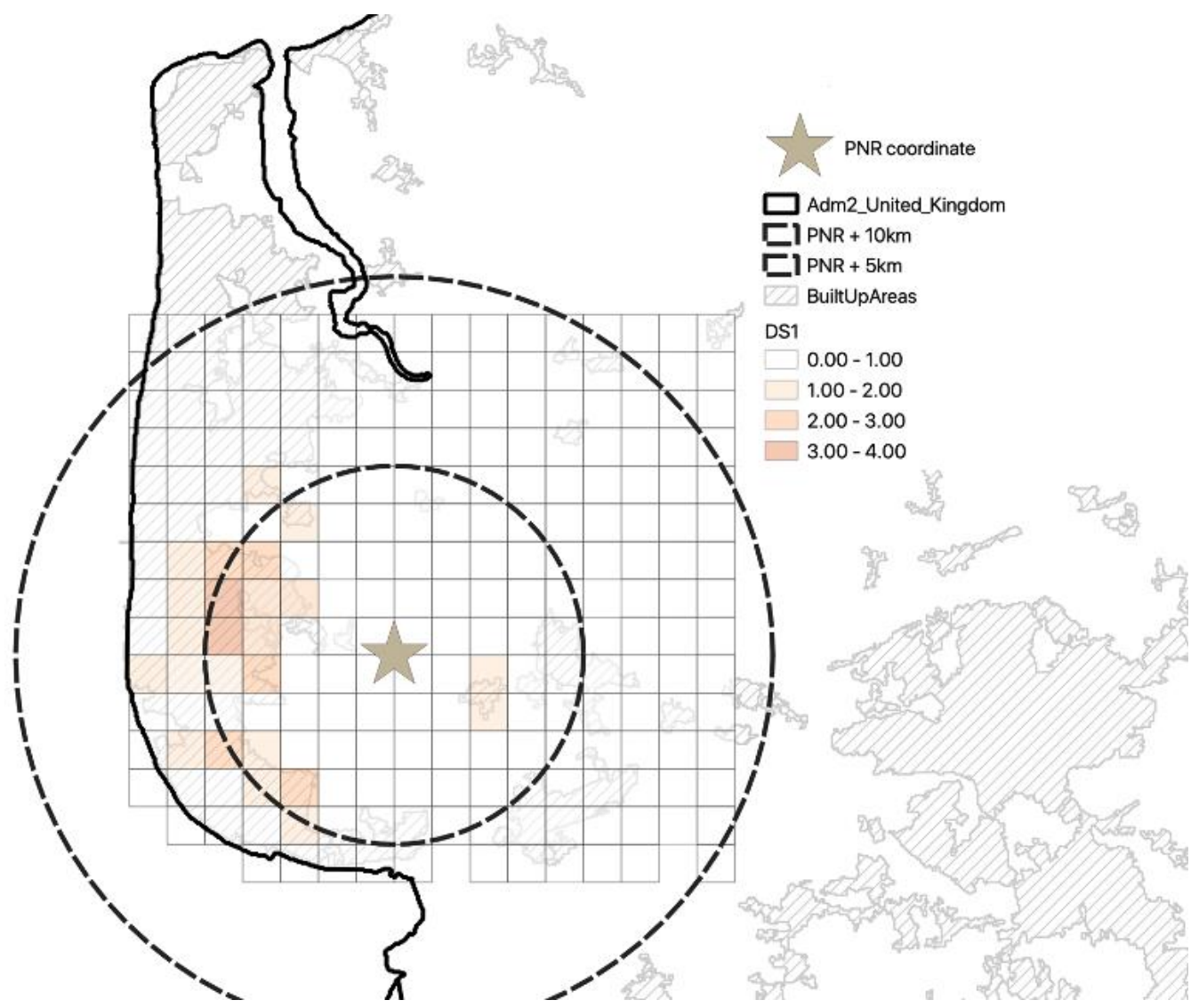

16 Figure 19. Spatial distribution of the mean number of buildings in DS1 for the scenario event $\mathrm{M}_{\mathrm{L}}=2.9$. Note that every grid 17 cell has a number of buildings $<1$ for all other damage states and chimney collapse. 

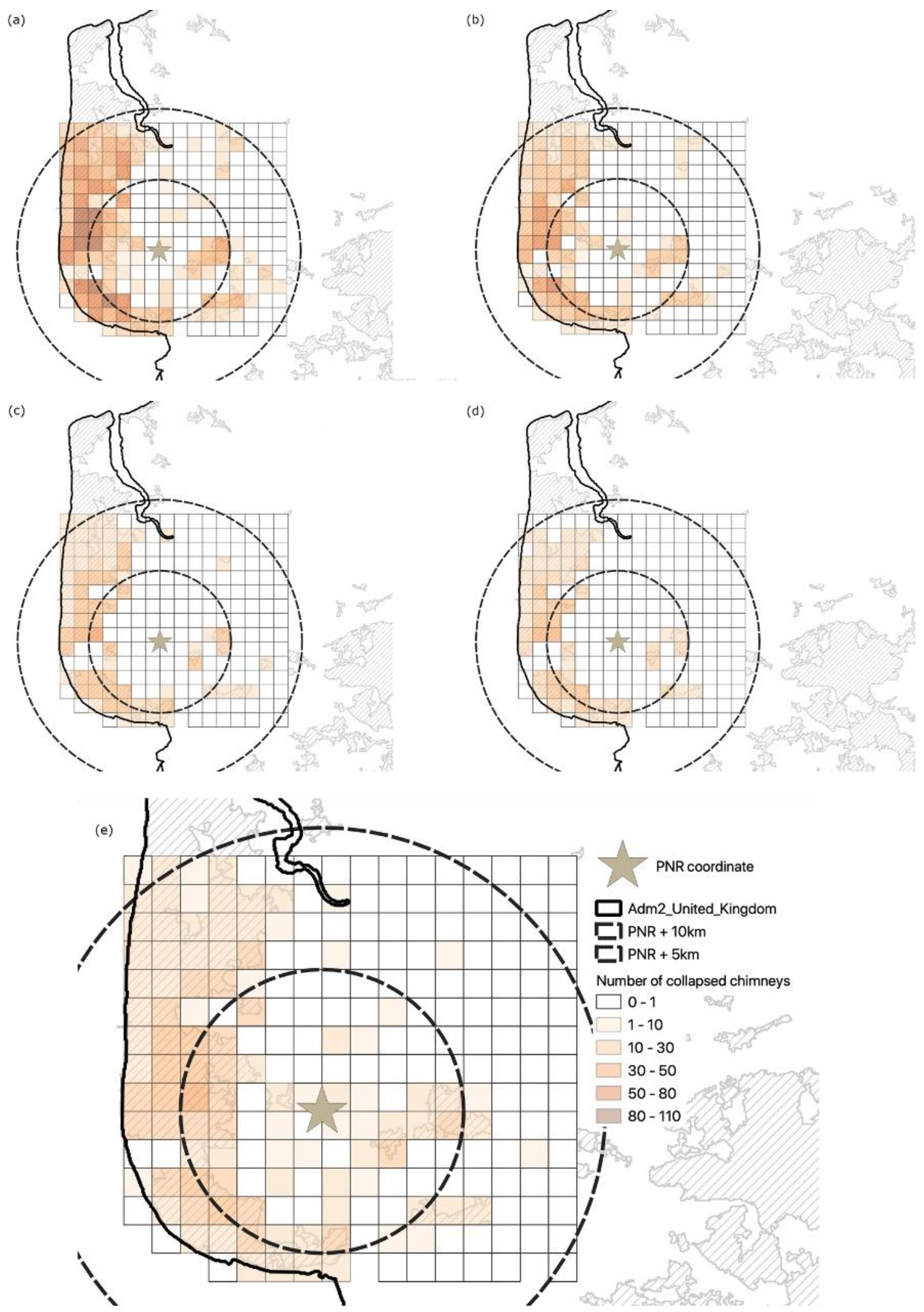

21 Figure 20. Spatial distribution of the mean percentage of buildings in each damage state for the scenario event $\mathrm{M}_{\mathrm{L}}=4.5$ (a) 22 DS1, (b) DS2, (c) DS3, (d) DS4, (e) chimney collapse. 

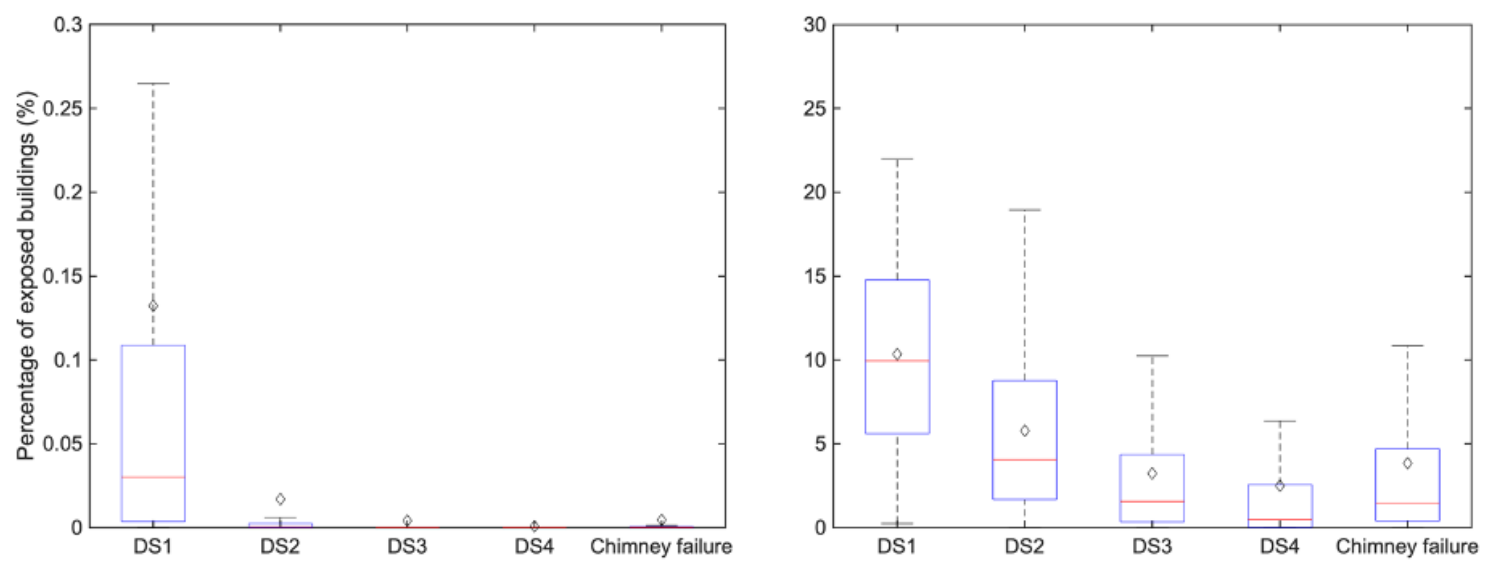

24 Figure 21. Total percentage of buildings in each damage state for scenario events $\mathrm{M}_{\mathrm{L}}=2.9$ (left) and $\mathrm{M}_{\mathrm{L}}=4.5($ right). Note

25 change of scale. The median $\left(50^{\text {th }}\right.$ percentile $)$ is shown by the red line while the box and whisker indicates the 25 th and 75 -

27
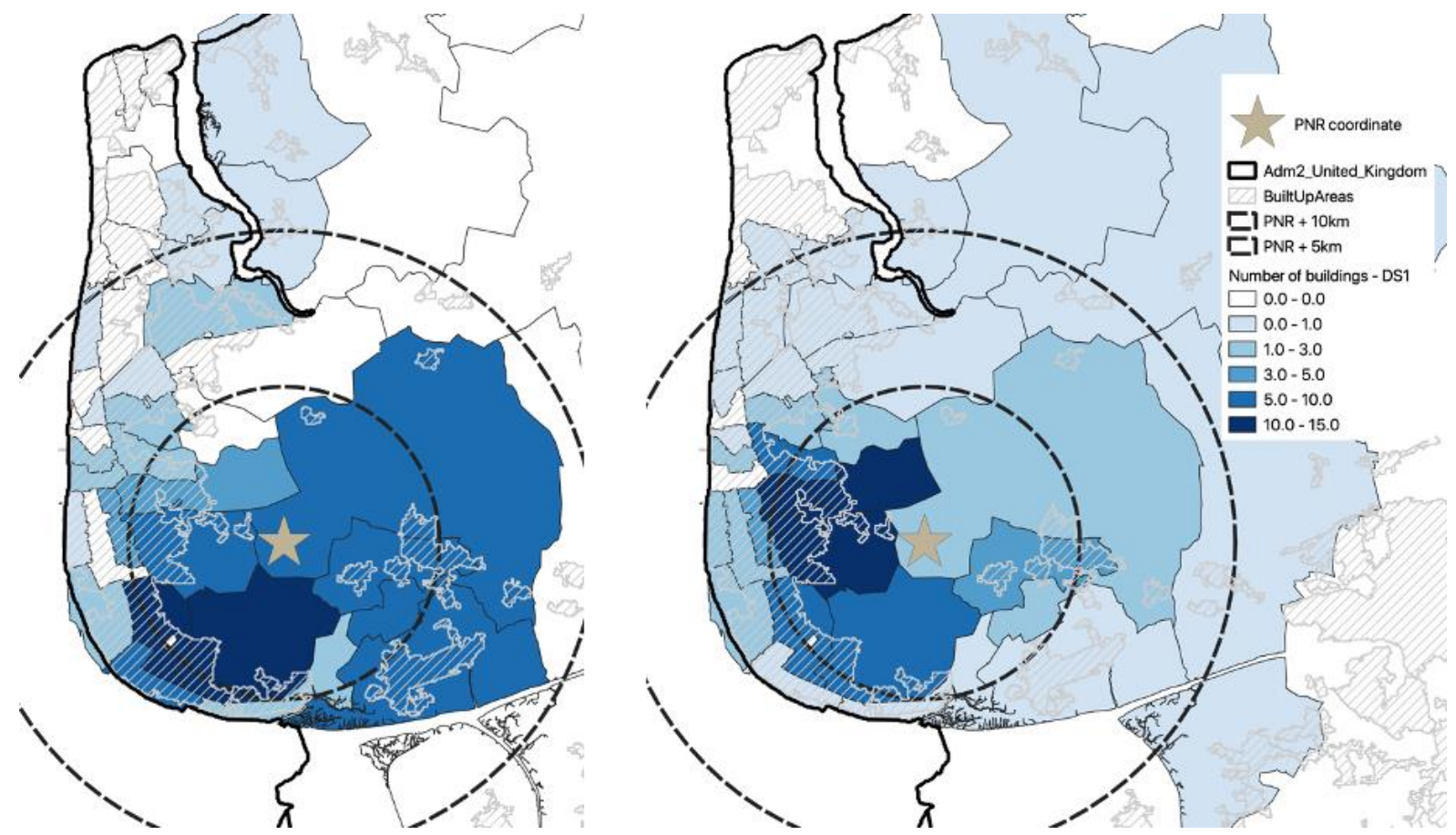

Figure 22. EMS-98 DS1 damage grouped by postcode district for the $\mathrm{M}_{\mathrm{L}} 2.9$ event, using the 'did-you-feel-it?' data (left) and the modelled damage (right). 

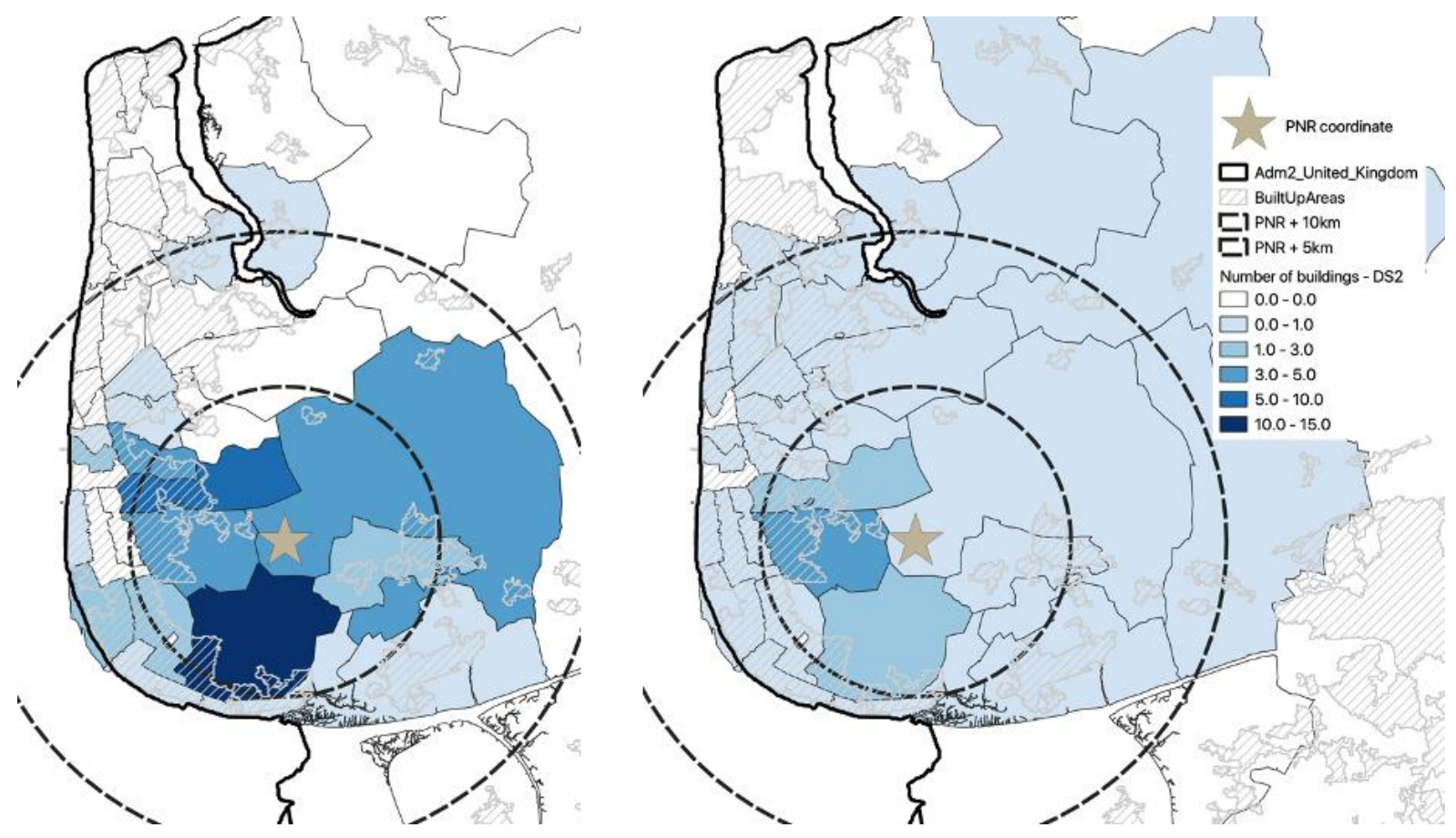

33

34 Figure 23. EMS-98 DS2 damage grouped by postcode district for the $\mathrm{M}_{\mathrm{L}} 2.9$ event, using the 'did-you-feel-it?' data (left) and 35 the modelled damage $(r i g h t)$. 